\title{
Rupture Processes of the 1987-1988 Gulf of Alaska Earthquake Sequence
}

\author{
Lorraine J. Hwang ${ }^{1}$ and Hiroo Kanamori
}

\author{
Division of Geological and Planetary Sciences, California Institute of Technology, Pasadena
}

\begin{abstract}
Three large earthquakes occurred in the Gulf of Alaska during 1987-1988: one on November $17,1987\left(M_{w}=7.2\right)$, the second one on November 30, $1987\left(M_{w}=7.8\right)$, and the third one on March 6, $1988\left(M_{w}=7.7\right)$. These major intraplate, strike-slip oceanic events occurred along conjugate trends in a region of no previous seismicity. Body wave modeling places their centroid depths in the upper mantle. The depth of the first two events is approximately $20 \mathrm{~km}$ and of the third is $15 \mathrm{~km}$. As compared to other large events, the body wave models for the two largest earthquakes have short rupture lengths, $110 \mathrm{~km}$ and $40 \mathrm{~km}$, respectively, and short duration times, 36 and 20 s, respectively, for their magnitude. The latter of the two events has a rupture length much shorter than that inferred from aftershock seismicity. The short rupture lengths and source durations may reflect differences between the strength of oceanic and continental lithosphere and suggest that events in oceanic lithosphere have a higher moment release per unit area than similar continental events. Most of the moment release occurred near the epicenter and/or regions of apparent structural complexities where seismicity trends intersect.
\end{abstract}

\section{INTRODUCTION}

The 1987-1988 Gulf of Alaska sequence consists of three large earthquakes with magnitudes of $6.9,7.6$, and $7.6 \mathrm{Ms}_{s}$ (National Earthquake Information Center, NEIC), respectively, occurring during November 1987 and March 1988. All three earthquakes lie within the Pacific plate outboard of the continental shelf margin and the Aleutian trench axis, in a region with no previous seismic activity (Figure 1). In general, large oceanic intraplate events are not common and usually involve normal or thrust faulting away from the trench within the unsubducted portion of the plate [Lahr et al., 1988]. This earthquake sequence is unique because of its mode of faulting: conjugate strike-slip along crosscutting fault planes and its position away from major structural boundaries within oceanic crust.

Large strike-slip earthquakes along plate boundaries often have rupture lengths on the order of several hundred kilometers. Surface rupture for the 1976 Guatemala earthquake $\left(7.5 \mathrm{M}_{s}\right)$ was observed along $230 \mathrm{~km}$ of the fault [Plafker, 1976]; the 1958 southeast Alaska earthquake $\left(7.9 \mathrm{M}_{s}\right)$ had a rupture length of at least $280 \mathrm{~km}$ [Plafker et al., 1978]; and the 1972 Sitka earthquake $\left(7.6 M_{s}\right)$, a length of approximately $200 \mathrm{~km}$ [Perez and Jacob, 1980]. One exception is the 1989 Macquarie Ridge (8.2 $M_{s}$ ) earthquake, which had a relatively short rupture length of $<200 \mathrm{~km}$. In comparison, the two largest Gulf of Alaska earthquakes also had relatively short rupture lengths. As inferred from aftershock seismicity, the two largest Gulf of Alaska events both activated zones less than $140 \mathrm{~km}$ in length [Lahr et al., 1988]. This suggests that these intraplate events have either relatively larger amounts of slip and/or a deeper extent of faulting.

Large strike-slip earthquakes in oceanic crust are rare and their depth of faulting is poorly understood. Estimates of depth for the 1989 Macquarie Ridge earthquake,

\footnotetext{
${ }^{1}$ Now at U.S. Geological Survey, Pasadena, California
}

Copyright 1992 by the American Geophysical Union.

Paper number 92JB01817.

0148-0227/92/92JB-01817\$05.00 a large oceanic interplate strike-slip event, vary from 10 to $50 \mathrm{~km}$ [Anderson and Zhang, 1991; Braunmiller and Nábělek, 1990; Dziewonski and Zwart, 1990; Ekström and Romanowicz, 1990; Kedar and Tanimoto, 1990; Tichelaar and Ruff, 1990]. In general, seismicity for interplate strikeslip faults in both continental and oceanic environments is quite shallow and does not extend below $15 \mathrm{~km}$. Hence rupture is assumed to be restricted to the crust. Some intraplate oceanic events have been observed at greater depths [Wiens and Stein, 1983; Engeln et al., 1986] suggesting failure of the upper mantle in some regions as well. For oceanic intraplate earthquakes, the maximum depth of seismicity is approximately equal to the flexural elastic thickness of the lithosphere [Wiens and Stein, 1983]. On the basis of the lithospheric cooling model of Parsons and Sclater [1977], an age range of 25-50 Ma determined from magnetic anomalies suggests source depths of up to $30 \mathrm{~km}$ in the northern Gulf of Alaska. Hence an assumed depth of $10 \mathrm{~km}$ [Lahr et al., 1988] for these events may be too shallow. Both depth and lateral extent of faulting are important parameters in the investigation of crustal processes and the assessment of future seismic hazard in the northern Gulf of Alaska region.

Strike-slip earthquakes within populated regions have caused enormous casualties and economic damage. The 1976 Tangshan earthquake $\left(7.7 M_{s}\right)$ virtually destroyed the city and killed over 250,000 people. The 1976 Guatemalan earthquake $\left(7.5 \mathrm{M}_{s}\right)$ caused extensive damage and loss of life, over 22,700 people were killed [Espinosa et al., 1976]. Both of these events had complex multiple sources and long source durations best described using multiple subevents with different mechanisms [Butler et al., 1979; Kikuchi and Kanamori, 1991]. The Gulf of Alaska events fortunately occurred well offshore, causing minimal damage to structures and no loss of life (NEIC). Knowledge of the temporalspatial distribution of heterogeneities along strike-slip faults such as the San Andreas is important in understanding the damage caused by strong ground motions during large, strike-slip earthquakes.

The large number of investigations of the 1976 Guatemalan earthquake illustrate how difficult it is to resolve source parameters for large strike-slip earth- 


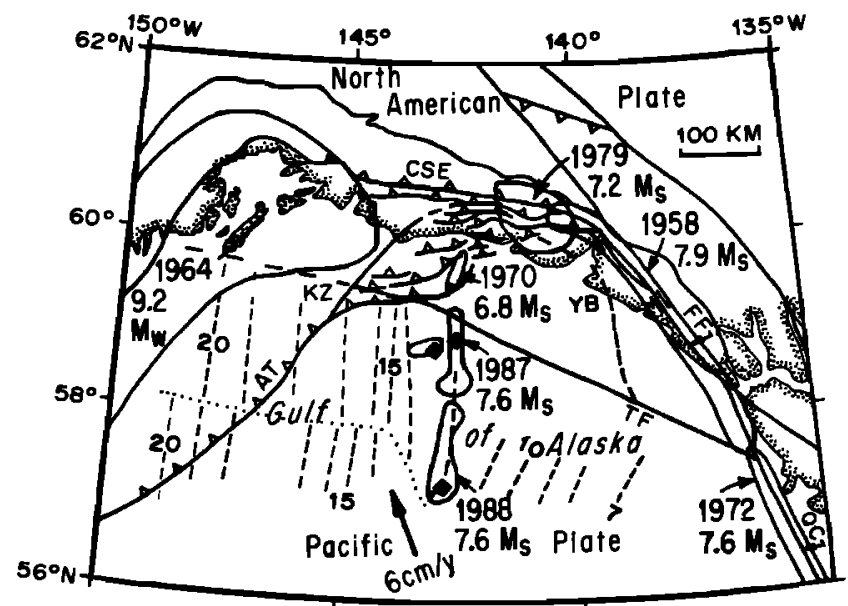

Fig. 1. Tectonic setting of the northern Gulf of Alaska showing major structural features, magnetic anomalies, and locations of recent shocks (epicenters shown as diamonds) in relation to the Pacific and North American plates, Yakutat terrane, and rupture zones of large historic earthquakes. The heavy arrow shows the relative motion of Pacific plate with respect to North American plate [DeMets et al., 1990]. AT, Aleutian Trench; CSE, Chugach-St. Elias fault system; FF, Fairweather fault; KZ, Kayak Zone; QC, Queen Charlotte fault; TF, Transition fault; YB, Yakutat Bay (after Lahr et al., [1988]).

quakes reliably [Kanamori and Stewart, 1978; Kikuchi and Kanamori, 1982; Young et al., 1989; Kikuchi and Kanamori, 1991]. In comparison to normal or reverse faulting events, most teleseismic stations lie near nodes of the $P$ wave radiation pattern and the radiation pattern changes rapidly with azimuth. Since amplitude changes the most rapidly near nodes, waveforms from these stations are very sensitive to the position of the nodal lines with respect to the station. The $P$ wave radiation from strike-slip earthquakes is also more sensitive to lateral variations in the crustal structure [Langston, 1977]. If azimuthal coverage is not good, arrivals that are due to crustal heterogeneities can be mistaken for source effects. When available, $S$ wave data help to constrain the focal mechanism of the source. Unfortunately, for large earthquakes, $S$ wave data are not always available since $S$ wave amplitudes often exceed the dynamic range of the instruments.

Since large strike-slip earthquakes are not common within the modern instrumental records, studying the 1987-1988 Gulf of Alaska sequence is important in understanding strike-slip earthquakes as well as in evaluating modern inversion techniques. Here, two multiple-source inversion techniques are used to analyze the waveform data. As described later, the techniques of Nábělek [1984, 1985] and Kikuchi and Kanamori [1991] are used to study the trade-offs and resolution of each method in resolving the source parameters of the Gulf of Alaska events and their relationship to regional tectonics and seismicity.

\section{Regional Setting and Seismicity}

The northern Gulf of Alaska lies near a major change in the plate boundary between the Pacific and North American plates (Figure 1). Along this boundary the North
American plate, the Pacific plate, and a series of accreted terranes interact [Perez and Jacob, 1980]. The Queen Charlotte Islands-Fairweather fault system marks the active eastern plate boundary between the North American and Pacific plates. Right-lateral movement along this boundary occurs at a rate of 4.8-5.8 cm/yr [Minster and Jordan, 1978; Plafker et al., 1978; Perez and Jacob, 1980]. The northern plate boundary follows the Aleutian trench. Along this margin, the Pacific plate subducts under the North American plate at a rate of about $5.7 \mathrm{~cm} / \mathrm{yr}$ in the southern Alaska region [DeMets et al., 1990].

In between these two regions, the plate boundary becomes diffuse. It is represented by a series of thrust faults belonging to the Chugach-St. Elias fault system. These faults join the Aleutian megathrust along the Kayak zone to the south and intersect the Fairweather fault near Yakutat Bay to the west. Collision of buoyant borderland terranes onto the North American plate along a series of thrust and reverse faults in southern Alaska results in major orogenies [Perez and Jacob, 1980]. Currently, the Yakutat block is actively accreting onto the North American plate along this margin [Plafker et al., 1978; von Huene et al., 1979; Lahr and Plafker, 1980; Perez and Jacob, 1980].

The boundary between the Pacific and the North American plates marks one of the world's most active earthquake belts. Most of this boundary has broken in major earthquakes this century. Along the eastern side of the Gulf of Alaska, the 1958 Fairweather earthquake $\left(8.2 M_{w}\right)$ broke the length of the Fairweather fault from Palma to Yakutat Bay [Tocher, 1960; Sykes, 1971; Plafker et al., 1978]. The 1979 St. Elias earthquake $\left(7.2 M_{s}, 7.5 M_{w}\right)$ [Buland and Taggart, 1981] ruptured an adjacent region to the north from Yakutat Bay to Icy Bay. West of this zone, the boundary from Kodiak to Kayak Island [Plafker, 1969] broke in 1964 in one of the largest instrumentally recorded earthquakes (8.4 $M_{s}, 9.2 M_{w}$ ) [Kanamori, 1977]. The region between the 1979 and 1964 earthquake zones has been identified as a seismic gap [Lahr and Plafker, 1980; McCann et al., 1980; Sykes et al., 1981] (see Figure 1).

The only significant offshore activity prior to 1987 in the northern Gulf of Alaska took place along the Pamplona zone in the western portion of the Yakutat block where a sequence of large thrust earthquakes occurred in 1970 (Figure 1). Recent activity in 1987-1988 activated a $3200 \mathrm{~km}^{2}$ area in what was previously considered nonseismic oceanic crust just south of the Yakataga seismic gap. Network coverage for this region is not good. Aftershocks shown in Figure 2 have been relocated by Lahr et al. [1988] with depths fixed at $10 \mathrm{~km}$. The events have maximum relative location errors of $20 \mathrm{~km}$ with the east-west direction better constrained than the north-south direction. The first motion solutions are from J. Lahr (personal communication, 1988) and include readings from local and global networks. Inversion results are also briefly summarized below.

Event 1, the first event of the sequence on November 17, 1987: $0846: 51 \mathrm{UTC}, 58.80^{\circ} \mathrm{N}, 143.11^{\circ} \mathrm{W}, 6.9 M_{s}$ [Lahr et al., 1988], ruptured an east-west trending zone $40 \mathrm{~km}$ in length. Moment release was confined to a small region near the epicenter. Aftershock data along with first motion data and body-wave modeling results indicate left-lateral movement within the Pacific plate.

Event 2, the second event of the sequence on November 30, 1987: $1923: 16 \mathrm{UTC}, 58.91^{\circ} \mathrm{N}, 142.76^{\circ} \mathrm{W}, 7.6 M_{s}$ 


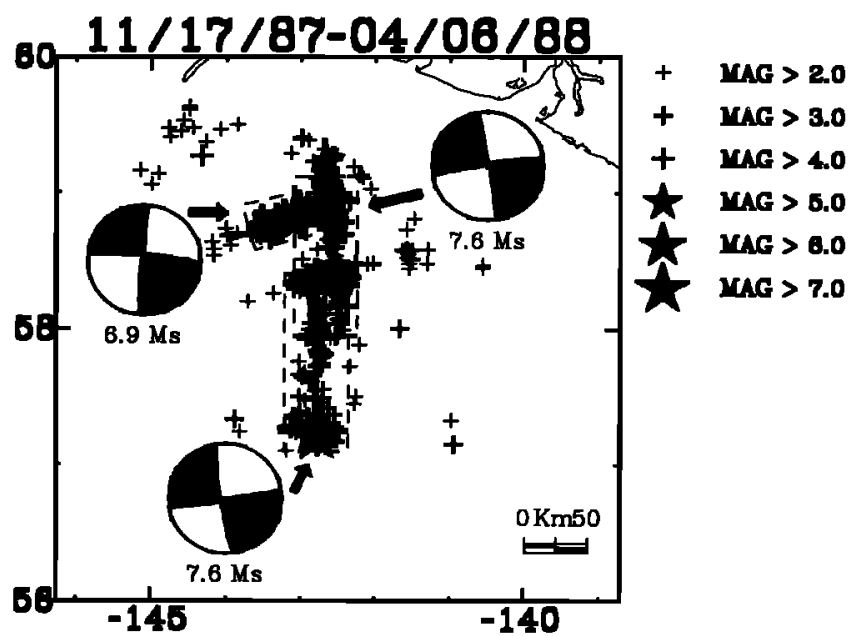

Fig. 2. Earthquake activity in the northern Gulf of Alaska from November 17, 1987, through April 6, 1988. Events have been relocated by Lahr et al. [1988]. Mainshocks are plotted as stars. Focal mechanisms are from first motion analyses by J. Lahr (personal communication, 1988). For each event, the aftershock zone during the first 24 hours is outlined. Faults as inferred from seismicity are shown with a solid line. Symbols are as given in the figure. All magnitudes are $M_{L}$ unless otherwise noted.

[Lahr et al., 1988], ruptured a primarily north-south trending zone $140 \mathrm{~km}$ in length. This event was preceded by a $4.5 m_{b}$ shock located $30 \mathrm{~km}$ ENE of event 1 . Rupture for event 2 initially nucleated at the eastern edge of the aftershock zone from event 1 . Aftershocks within the first 24 hours suggested bilateral rupture $40 \mathrm{~km}$ to the north and $100 \mathrm{~km}$ to the south of the epicenter. Seismicity was concentrated from the epicentral region towards the north and along a roughly east-west trending zone $60 \mathrm{~km}$ to the south. These regions of high seismicity roughly correspond to regions of high moment release. Farther south, activity was more diffuse. In combination with seismicity associated with event 3 , their pattern suggests two parallel northsouth trending fault zones. At the northernmost end, very little or no activity crossed over into the Yakutat block.

Event 3, the third event of the sequence, occurred 3 months later on March 6, 1988: 22 35:36 UTC, $57.23^{\circ} \mathrm{N}$, $142.78^{\circ} \mathrm{W}, 7.6 \mathrm{Ms}_{s}$ [Lahr et al., 1988]. The aftershock pattern suggests unilateral rupture $110 \mathrm{~km}$ to the north on a zone offset from the initial trend of activity from event 2 but continuous with the trend of seismicity between the two events. Many aftershocks clustered tightly around the region of the largest aftershock $\left(6.2 m_{b}\right)$, about $70 \mathrm{~km}$ to the north. Aftershocks just north of the mainshock formed a cluster $50 \mathrm{~km}$ wide in the east-west direction. Models of moment release for this event do not indicate a large lateral extent of rupture; instead, moment release is confined to the epicentral region.

\section{Data}

The data used in the inversions are Global Digital Seismic Network (GDSN), GEOSCOPE, and Worldwide Standard Seismograph Network (WWSSN) $P$ and $S H$ wave- forms. The distance ranges are restricted to the region $30^{\circ} \leq \Delta \leq 90^{\circ}$ for $P$ waves and $30^{\circ} \leq \Delta \leq 85^{\circ}$ for $S H$ waves to avoid regional and core effects. WWSSN data are digitized, using an optical scanner, resampled at an interval of $0.25 \mathrm{~s}$, and corrected for drift and curvature for known pen-arm lengths.

Since the data from each network have different instrument responses, records are reconvolved to a standard response. Two data sets with different responses and overlapping bandwidths are modeled, a long-period GDSN and a long-period WWSSN-type data set. This allows us to test their stability and resolution. For the long-period GDSN data set, the data have either standard, long-period, network instrument responses or are modified to a standard, long-period Digital Worldwide Standard Seismograph Network (DWWSSN) type (SCP) response. Data from the Chinese Digital Seismc Network (CDSN), Seismic Research Observatories (SRO), Abbreviated Seismic Research Observatories (ASRO), and DWWSSN stations retain their original instrument responses. GEOSCOPE and some DWWSSN stations have much broader-band instrument responses so their data are reconvolved to a long-period SCP instrument response and band-pass-filtered between 0.01 $0.3 \mathrm{~Hz}$. On the other hand, the long-period CDSN instrument response has a very narrow bandwidth. In general, the waveforms for the CDSN stations do not appear as complex as those for the rest of the stations and can be easily modeled. While the CDSN long-period data do little to help resolve the source-time history of the event, the data do provide constraints on the long-period focal mechanism.

The WWSSN-type data set has a broader bandwidth that extends to higher frequencies than the long-period GDSN data and hence can resolve the details in the source much better. For this data set, a combination of broadband, long-, intermediate-, and short-period digital data is reconvolved to a standard WWSSN long-period response and band-pass-filtered between 0.01 and $1 \mathrm{~Hz}$ or are highpass filtered with a low-frequency cutoff of $0.01 \mathrm{~Hz}$.

The GEOSCOPE data used here were not corrected for clock errors. In the following models, the records are initially aligned on the first arrival for the $P$ waves or the onset of the $S H$ arrival as determined from broadband or shortperiod records when available. Otherwise, the theoretical arrival times are used.

The lateral fault dimensions and the range of possible models to investigate are constrained by the aftershock patterns described above. The crustal model is taken after von Huene et al. [1979] (Table 1). The total thickness of the oceanic crust is $8.5 \mathrm{~km}$. The thickness of the water layer and hence, the depth to the top of the crust, varies for each earthquake as noted.

TABLE 1. Velocity Model

\begin{tabular}{ccccc}
$\begin{array}{c}\text { Thickness, } \\
\text { km }\end{array}$ & $\begin{array}{c}\text { Depth, } \\
\mathbf{k m}\end{array}$ & $\begin{array}{c}V_{p}, \\
\mathbf{k m} / \mathrm{s}\end{array}$ & $\begin{array}{c}V_{s}, \\
\mathbf{k m} / \mathrm{s}\end{array}$ & $\begin{array}{c}\text { Density, } \\
\mathrm{g} / \mathrm{cm}^{3}\end{array}$ \\
\hline $3.5^{*}$ & 0.0 & 1.5 & 0.0 & 1.0 \\
2.5 & 3.5 & 2.4 & 1.4 & 2.1 \\
6.0 & 6.0 & 6.5 & 3.8 & 2.9 \\
& 12.0 & 8.1 & 4.7 & 3.4 \\
\hline
\end{tabular}

* $3.5 \mathrm{~km}$, November 17, 1987; $3.2 \mathrm{~km}$, November 30, 1987; $3.8 \mathrm{~km}$, March 6, 1988 . 


\section{METHODS}

Two different methods are used to investigate the source characteristics of the Gulf of Alaska earthquakes. Both the long-period GDSN (LP) and broader band WWSSN-type (WWS) data sets are inverted using the method of Nábelek [1984, 1985] and Kikuchi and Kanamori [1991], hereafter referred to as method $N$ and $K$, respectively.

In method $\mathrm{N}$, teleseismic body waves are simultaneously inverted in a least squares sense. This method can invert for multiple sources and solves simultaneously for the focal mechanism, centroid depth, and source-time function for each source. Both a stationary as well as a propagating point source can be investigated. The propagating point source is composed of triangular source elements that are restricted to rupture at a fixed velocity and a single depth.

In the following inversions, the LP data are initially used to estimate the gross source parameters, and the WWS data are then used to refine the model. Either the first motion or the centroid moment tensor (CMT) solution is used as a starting focal mechanism that is allowed to vary. For events with multiple subevents, subevent 1 is always constrained to start at the first motion time. The delay times of additional subevents are allowed to vary. Depths between 5 and $40 \mathrm{~km}$ and velocities up to $3.5 \mathrm{~km} / \mathrm{s}$ are systematically investigated by holding both parameters fixed in the inversion. Faster velocities up to $5 \mathrm{~km} / \mathrm{s}$ are considered only for event 3 . The least error solution for the different combinations of velocity and depth gives the final model.

In method $\mathrm{K}$, the source-time function is built from a series of point sources that lie on a two-dimensional fault plane. The moment tensor for each individual point source can be inverted for or held fixed. The speed of the rupture front cannot exceed the specified maximum rupture velocity. Subevents can occur anywhere on or inside the rupture front. As used here, the moment tensor is constrained to be a double-couple source that is allowed to vary in time. Maximum rupture velocity is $3.5 \mathrm{~km} / \mathrm{s}$, and the fault modeled extends from 10 to $50 \mathrm{~km}$ in depth. The best fit focal mechanisms and their correlation functions for the first iteration are examined on the $\tau-l$ plane, where $\tau$ and $l$ are time lag and distance of the subevents from the epicenter, to determine the complexity of the event and the resolution of the initial focal mechanism, its timing, and subevent position. Subsequent iterations map a different set of correlation functions and focal mechanisms on the $\tau-l$ plane. The first and largest subevent solved for in the inversion corresponds to a peak in the correlation function and is the most robust. As the waveform from each subevent is subtracted from the original data, each successive subevent tends to have less moment, is less reliable, and depends on the source parameters of the previous subevents. Hence the first several iterations give the most robust solutions. In the following section, only the correlation functions from the first iteration for the WWS models will be shown since they are very similar to those for the LP models which are also very stable [Hwang, 1991].

Methods $\mathrm{N}$ and $\mathrm{K}$ differ by how they average the source and how subevents trade off with one another. In both methods, source properties are averaged over the time window of each subevent. For each subevent, the results give the centroid location and focal mechanism over its duration. In method $\mathrm{N}$, the source is described by fewer subevents whose positions are either constrained to lie at a point or along a line propagating at a specified rupture velocity. The conditions are more rigid than in method $K$ and result in each subevent averaging over longer time periods and a larger area. This averaging or smoothing is desirable for event 2 since the details of the source are not always resolvable.

For sources that change rapidly in time, smoothing may not result in an accurate picture of the source process. Both time variation in the focal mechanism and in the source positions can alias into the source parameters. In method $\mathrm{N}$, the number of subevents is kept small to limit these trade offs. Since the source parameters of each subevent actively interact with one another during the inversion, minimizing the number of free parameters stabilizes the solution. In method $K$, source parameters of each subevent depend on previous iterations. This problem has been discussed by Young et al., [1989] and Kikuchi and Kanamori [1991] and has been called path dependence. Choosing different first subevents or changing the order of iteration changes the iteration path. The new solution can produce divergent but equally valid results. This effect is particularly important for complex events whose correlation functions have maxima with similar values [Young et al., 1989]. As shown below, events 1 and 3 have relatively simple sources whose initial correlation functions have one well-isolated peak and whose focal mechanisms are stable over a long time window. On the other hand, the correlation functions for event 2 have several peaks. However, the largest peak has a much greater value then the other local maxima. In addition, the focal mechanisms associated with the other local maxima have an opposite sense of motion than that suggested by the first motion data. The above suggests that the initial inversion path for all events is stable.

The final model results for the three earthquakes investigated here are summarized in Tables 2-4. The first motion (J. Lahr, personal communication, 1988) and the CMT solution [Dziewonski et al., 1989a,b] are also shown for comparison. The last column gives the moment for the subevent(s) as described. Total moment, if different, is given in parentheses. For solutions with a time-varying source in method $K$, the focal mechanisms and the total moment given represent the best double-couple sum of the subevents comprising the event. Detail tables of source parameters of all subevents are given in the appendices.

\section{INVERSION RESULTS}

The following sections summarize and discuss the inversion results for each event. The first paragraph gives an overview of the general features of the model that are robustly determined and notes important parameters that are not well resolved. A more detailed discussion follows.

Details of the inversions and each model are given in the appendices. In the following section, only those subevents reliably determined are given in Tables 2-4 for models $\mathrm{N}$. For models $\mathrm{K}$, only the best double-couple solution is shown.

\section{November 17, 1987}

For event 1, Table 2 summarizes the source parameters for the source models $1 \mathrm{NLP}, 1 \mathrm{NWWS}, 1 \mathrm{KLP}$, and $1 \mathrm{KWWS}$. 
TABLE 2. November 17, 1987, Summary of Source Parameters for Event 1

\begin{tabular}{|c|c|c|c|c|c|c|c|c|c|c|}
\hline Model & $\begin{array}{c}\text { Strike, } \\
\text { deg }\end{array}$ & $\begin{array}{l}\text { Dip, } \\
\text { deg }\end{array}$ & $\begin{array}{c}\text { Rake, } \\
\text { deg }\end{array}$ & $\begin{array}{c}\text { Depth, } \\
\text { km }\end{array}$ & $\begin{array}{c}\text { Delay, } \\
s\end{array}$ & $\begin{array}{c}\text { Velocity, } \\
\mathrm{km} / \mathrm{s}\end{array}$ & $\begin{array}{c}\text { Distance, } \\
\mathbf{k m}\end{array}$ & $\begin{array}{c}\text { Azimuth, } \\
\text { deg }\end{array}$ & $\begin{array}{r}\text { Mom } \\
\text { dyn cm }\end{array}$ & $10^{26}$ \\
\hline FM & 275 & 83 & 2 & $10^{*}$ & & & & & & \\
\hline CMT & 262 & 57 & -6 & $15^{*}$ & & & & & 6.6 & \\
\hline 1NLP.2 & 265 & 74 & 2 & 25 & 4 & 1.0 & & & 5.3 & (6.4) \\
\hline 1NWWS.2 & 266 & 75 & -2 & 25 & 2.3 & 1.0 & & & 6.7 & $(8.0)$ \\
\hline 1KLP & 260 & 84 & -8 & 20 & 4 & $3.5^{\#}$ & $-20-40$ & 260 & 8.4 & \\
\hline 1KWWS & 275 & 78 & 0 & 20 & 4.0 & $3.5^{\#}$ & $0-40$ & 270 & 6.3 & \\
\hline
\end{tabular}

FM, first motion solution (J. Lahr, personal communication, 1988); CMT, centroid moment tensor [Dziewonski et al., 1989a,b]; for others, see text. For models $\mathrm{N}$, only those subevents reliably determined are given. Total moment for all subevents is shown in parentheses. For models $\mathrm{K}$, only the source parameters for the best double-couple solution are given along with a summary of the source extent. For more details, see tables in appendices.

- Fixed.

\# Maximum rupture velocity.

Models are in good agreement with each other (see Appendix A). Figure 3 summarizes all four models. This earthquake consisted of multiple subevents. The largest subevent has a left-lateral, strike-slip mechanism on an eastwest trending fault plane that dips steeply toward the north and lies at a centroid depth of 20-25 km. This subevent appears to propagate toward the west at a velocity of $1 \mathrm{~km} / \mathrm{s}$ but the rupture velocity is not well determined.

Most of the moment release for all models occurs in the epicentral region within $20 \mathrm{~km}$ of the epicenter (see shaded

\section{November 1987}

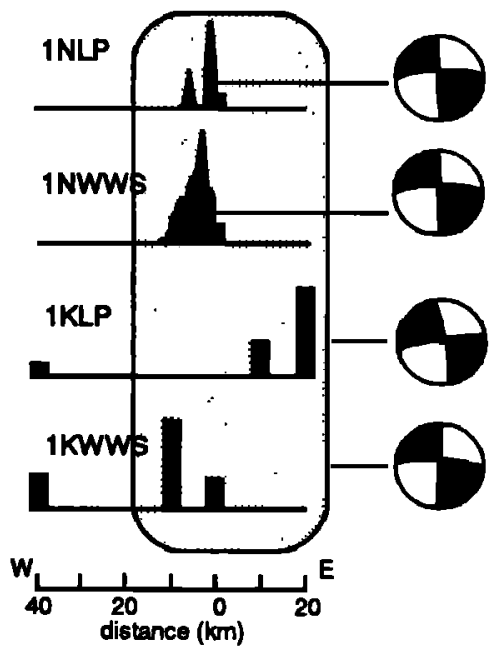

point source

line source

Fig. 3. Event 1. Comparison of the spatial moment distribution for each model. The height of each subevent is proportional to its moment and is normalized to the largest subevent in each model. Solid rectangles show the position of the point sources, and shaded figures represent the moment distribution of the line sources along the fault. Stippled region marks the lateral bounds of moment distribution as inferred from the models and corresponds to the shaded region in Figure 6 (see text). Only the focal mechanism for the largest subevent in models $1 \mathrm{~N}(\mathrm{LP}, \mathrm{WWS}$ ), subevent 2, are shown. Focal mechanisms shown for $1 \mathrm{~K}(\mathrm{LP}, \mathrm{WWS})$ are the best double-couple sum of the subevents. region in Figure 3). Both models using the WWSS data set indicate rupture propagation to the west of the epicenter. The LP data can only resolve a change of $20 \mathrm{~km}$ in source position and hence do not resolve the directivity very well due to the short duration time and small dimensions of the fault. However, both $1 \mathrm{KLP}$ and $1 \mathrm{KWWS}$ do place some moment release at a distance of $40 \mathrm{~km}$ to the west of the epicenter. This suggests that while models 1NLP and 1NWWS average the source at a particular time well, rupture could extend further along the fault and is allowed within the errors of the models (see Appendix A). A rupture extent of up to $40 \mathrm{~km}$ is in good agreement with the rupture length inferred from the aftershock area during the first 24 hours. Estimates of the total moment release vary but all correspond to $7.2 M_{w}$. This is larger than the reported surface wave magnitude $\left(6.9 M_{s}\right.$, NEIC).

This event initiated with a small moment releasing subevent. Modeling using a fixed focal mechanism in all models cannot explain the beginning of all of the waveforms indicating that the initial mechanism is not the same as that for the largest subevent. Models 1KLP and 1KWWS allow the focal mechanism to vary but do not solve for any moment release until $4 \mathrm{~s}$ after the onset of the first arrival. Hence these models cannot match the timing or shape of the first arrival very well. Subsequent iterations have very little moment and do little to improve the fit. Constraining moment release to begin earlier fits the early portion of the waveforms better at the northern stations but at considerable expense to the remainder of the waveform and to the waveform matches at other stations. In contrast, constraining moment release to begin at the first arrival time for the first subevent in models 1 NLP and 1NWWS can explain the data.

The main sequence does not initiate until approximately $4 \mathrm{~s}$ after the first arrival. It can be well modeled by a single source that has a duration of approximately 10-16 s. Estimates of the strike of the second subevent fall within $15^{\circ}$ of each other. For this second subevent, a strike rotated counterclockwise from due west agrees better with the overall trend of the aftershock data. However, even the most southerly striking fault plane solution still differs from the trend of the aftershock data by approximately $10^{\circ}$. Estimates of dip range from $57^{\circ}$ to $84^{\circ}$. The shallower fault dip estimated by the CMT method is probably due to the preassigned source depth. Source depths of $15 \mathrm{~km}$ using method $\mathrm{N}$ produce comparable dips. On the basis of the 
above models, a more realistic dip would be approximately $75^{\circ}$ to $85^{\circ}$.

\section{November 30, 1987}

For event 2, Table 3 summarizes the source parameters for the source models 2NLP, 2NWWS, 2KLP, and 1KWWS. Overall, the above models agree with one another (see Appendix B). Figure 4 summarizes the four source models. The earthquake consisted of multiple, right-lateral, strikeslip subevents with different focal mechanisms rupturing along a north-south trending plane at a centroid depth of 20-25 km. Models 2NLP and 2NWWS parameterize moment release using three point-source subevents. Moment release begins with a small, poorly resolved subevent in the epicentral region. The major portion of the total moment release does not initiate until approximately $15 \mathrm{~s}$ after the first arrival. Most of this moment release occurred to the south of the epicenter between a distance of 40 to $90 \mathrm{~km}$ (see shaded region in Figure 4). Additional moment release occurred in the epicentral region and to the north but its lateral extent was not robustly determined. Total moment release for these models corresponds to $7.8 \mathrm{M}_{w}$.

The different models indicate that substantial moment release could have occurred near to or north of the epicenter. Estimates of moment release vary between the models and are not well resolved. Subevent 2NLP.3 gives the largest estimate and is located just $20 \mathrm{~km}$ north of the epicenter. Subevent 2NWWS.3 is located farther to the north at $60 \mathrm{~km}$. Using the same data set and a fault extended to $90 \mathrm{~km}$ to the north, method $\mathrm{K}$ shows there is a tendency to place moment release even farther north than $60 \mathrm{~km}$. Positions greater than $40 \mathrm{~km}$ are located much farther north than the extent of the aftershock zone. Both focal parameters and source position may be trading off with one another due to the complexity of the rupture. Constraining the possible rupture extent lowers the total percentage of moment released to the north as the sources become closer to the epicenter.

The first motion results, using both teleseismic and local data, suggest that the event initiated as a near vertical, right-lateral, strike-slip earthquake trending NNWSSE. However, the estimates of the focal parameters vary. The NNW-SSE trending plane dips $70^{\circ}$ to the west in the CMT solution. The focal mechanism solutions in the above models trend both NNW-SSE and NNE-SSW and dip both to the east and west, but all agree with one another within the errors of their respective models. The spatial-temporal

\section{November 1987}

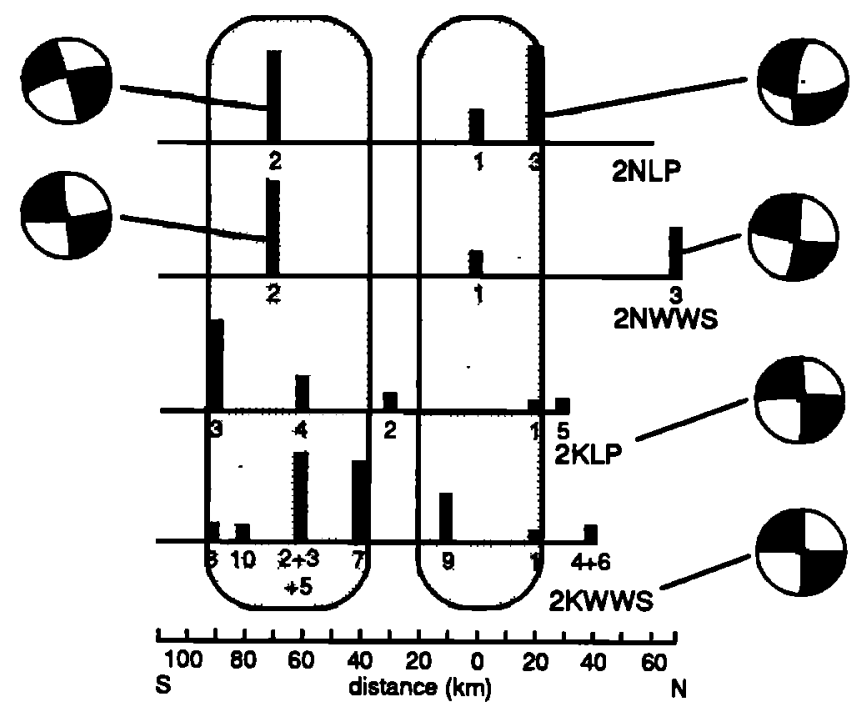

Fig. 4. Event 2. Symbols are described in Figure 3. For models 2NLP and 2NWWS, focal mechanisms for subevents 2 and 3 are shown. Focal mechanisms shown for $2 \mathrm{~K}$ (LP,WWS) are the best double-couple sum of the subevents. The number under each subevent indicates the initiation order of the subevent.

sequence in models $1 \mathrm{KLP}$ and $1 \mathrm{KWWS}$ illustrate that the pattern of moment release cannot be easily described by a simple point or propagating point source model (see Figure 4) suggesting that these discrepancies may be due to source finiteness as well as time variations in the focal mechanism. For models 2NLP and 2NWWS, it seems reasonable that the subevents idealized as point sources have a finite extent that is unresolvable from the data using method $\mathrm{N}$. In addition, since subevents 2 and 3 in models 2 NLP and 2NWWS overlap in time, some trade-offs in the source parameters are expected.

\section{March 6, 1988}

For event 3 , Table 4 summarizes the source parameters for the source models $3 \mathrm{NLP}$, 3NWWS, $3 \mathrm{KLP}$, and $3 \mathrm{KWWS}$. Models show good agreernent with each other (see Appendix C). Figure 5 summarizes all four models. Event 3 consisted of multiple strike-slip subevents. These subevents

TABLE 3. November 30, 1987, Summary of Source Parameters for Event 2

\begin{tabular}{|c|c|c|c|c|c|c|c|c|c|c|}
\hline Model & $\begin{array}{c}\text { Strike, } \\
\text { deg }\end{array}$ & $\begin{array}{l}\text { Dip, } \\
\text { deg }\end{array}$ & $\begin{array}{c}\text { Rake, } \\
\text { deg }\end{array}$ & $\begin{array}{c}\text { Depth, } \\
\text { km }\end{array}$ & $\begin{array}{c}\text { Delay, } \\
\text { s }\end{array}$ & $\begin{array}{c}\text { Velocity, } \\
\mathrm{km} / \mathrm{s}\end{array}$ & $\begin{array}{c}\text { Distance, } \\
\mathbf{k m}\end{array}$ & $\begin{array}{c}\text { Azimuth, } \\
\text { deg }\end{array}$ & $\begin{array}{r}\text { Mom } \\
\text { dyn cm }\end{array}$ & $\begin{array}{l}\text { ent, } \\
\times 10^{27}\end{array}$ \\
\hline$\overline{\mathbf{F M}}$ & 170 & 92 & 177 & $10^{*}$ & & & & & & \\
\hline CMT & 175 & 110 & 172 & $15^{*}$ & & & & & 7.3 & \\
\hline 2NLP.2 & 160 & 92 & 168 & 25 & 10 & & 70 & 180 & 3.2 & \\
\hline 2NLP.3 & 188 & 76 & 208 & 25 & 16 & & 20 & 0 & 3.5 & (7.7) \\
\hline 2NWWS.2 & 171 & 90 & 188 & 25 & 11 & & 70 & 180 & 4.6 & \\
\hline 2NWWS.3 & 188 & 98 & 187 & 25 & 20 & & 60 & 0 & 2.5 & (8.2) \\
\hline 2KLP & 177 & 97 & 173 & 20 & & \# & $-30-90$ & 180 & 5.3 & \\
\hline 2KWWS & 180 & 94 & 179 & 20 & & $\#$ & $-30-80$ & 180 & 5.6 & \\
\hline
\end{tabular}

For abbreviations, see Table 2.

- Fixed.

\# See text. 
TABLE 4. March 6, 1988, Summary of Source Parameters for Event 3

\begin{tabular}{|c|c|c|c|c|c|c|c|c|c|c|}
\hline Model & $\begin{array}{l}\text { Strike, } \\
\text { deg }\end{array}$ & $\begin{array}{l}\text { Dip, } \\
\text { deg }\end{array}$ & $\begin{array}{c}\text { Rake, } \\
\text { deg }\end{array}$ & $\begin{array}{l}\text { Depth, } \\
\text { km }\end{array}$ & $\begin{array}{c}\text { Delay, } \\
\mathbf{8}\end{array}$ & $\begin{array}{l}\text { Velocity, } \\
\mathrm{km} / \mathrm{s}\end{array}$ & $\begin{array}{c}\text { Distance, } \\
\text { km }\end{array}$ & $\begin{array}{l}\text { Azimuth, } \\
\text { deg }\end{array}$ & \multicolumn{2}{|c|}{$\begin{array}{c}\text { Moment, } \\
\text { dyn } \mathrm{cm} \times 10^{27}\end{array}$} \\
\hline$\overline{\mathrm{FM}}$ & 170 & 83 & 182 & $10^{\prime \prime}$ & & & & & & \\
\hline CMT & 182 & 75 & 192 & $15^{*}$ & & & & & 4.9 & \\
\hline 3NLP.1 & 181 & 62 & 186 & 15 & & 3.5 & & 268 & 3.2 & \\
\hline 3NLP. 2 & 184 & 80 & 170 & 15 & 13 & & & & 1.7 & $(4.9)$ \\
\hline 3NWWS.1 & 179 & 79 & 187 & 15 & & 3.5 & & 268 & 2.9 & \\
\hline 3NWWS.2 & 189 & 97 & 176 & 15 & 13 & & & & 1.5 & (4.4) \\
\hline 3KLP & 182 & 74 & 180 & 20 & & $3.5^{\#}$ & $-40-20$ & 180 & 3.9 & \\
\hline 3KWWS & 176 & 81 & 189 & 10 & & $3.5^{\#}$ & $-10-20$ & 270 & 4.3 & \\
\hline
\end{tabular}

For abbreviations, see Table 2.

* Fixed.

\# Maximum rupture velocity.

06 March 1988

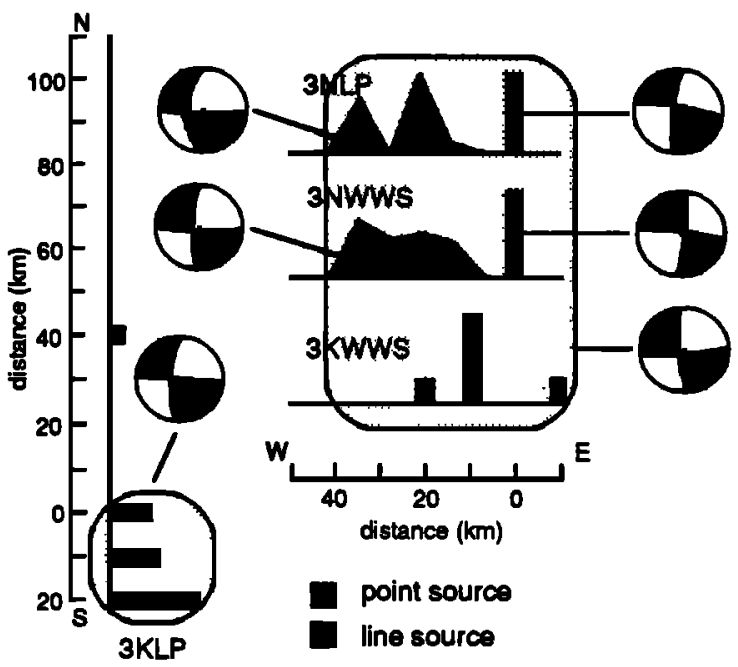

Fig. 5. Event 3. Symbols are described in Figure 3. For models 3NLP and 3NWWS, focal mechanisms for both subevents are shown. Focal mechanisms shown for $3 \mathrm{KLP}$ and $3 \mathrm{KWWS}$ are the best double-couple sums of the subevents.

have centroid depths predominantly between 10 and $20 \mathrm{~km}$ making event 3 the shallowest of the three Gulf of Alaska events. Estimates of the rupture direction and dimensions between the models differ. Total moment release for all models corresponds to an $7.7 M_{w}$.

Aftershock seismicity suggests that the fault ruptured predominantly unilaterally to the north. However, all models agree that no significant moment release occurred north of the epicenter and the maximum fault length was much shorter propagating predominantly toward the west. In models 3NLP and 3NWWS, the largest subevent propagates toward the west at a velocity of $3.5 \mathrm{~km} / \mathrm{s}$ or to a maximum extent of $42 \mathrm{~km}$ (see shaded region in Figure 5). Models 3KLP and $3 \mathrm{KWWS}$ do not indicate a large lateral extent of moment release. Most of the moment for these models lie within $20 \mathrm{~km}$ of the epicenter. The timing and location of their subevents suggest a rupture velocity closer to $2 \mathrm{~km} / \mathrm{s}$. This is within the allowable error range for models 3NLP and 3NWWS (see Appendix C) and would constrain most of the moment release to within a distance of $24 \mathrm{~km}$ of the epicenter in those models.
Subevents for this event have predominantly northsouth, east-west trending strike-slip focal mechanisms which is in good agreement with the fault geometry inferred from seismicity. Estimates of their focal parameters differ by $\pm 10^{\circ}$ between the different models and between the first motion and CMT solution, but all agree within the errors of their respective models. The first motion solution strikes about $10^{\circ}$ counterclockwise from the majority of the models. A near north-south strike similar to the above models with a near vertical dip, however, is also allowed by the first motion data. Since the epicenter of this event lies at the junction of both a westerly and northerly seismicity trend, the choice of fault planes is ambiguous. Even though the above models indicate rupture propagation towards the west, most of the moment release occurs in the epicentral region and thus cannot be clearly associated with either trend. Hence both trends may have been to a limited extent active or activated during this event.

\section{Discussion}

Aftershock seismicity of the Gulf of Alaska earthquakes concentrates primarily in the epicentral regions. For the two largest events, these are regions of apparent structural complexity where east-west and north-south seismicity trends intersect (Figure 6). The clustering of seismicity near structural complexities has been observed along other strike-slip faults. Lindh and Boore [1974] noted that the foreshock and mainshock of the 1966 Parkfield-Cholame earthquake lie near a $5^{\circ}$ bend in the fault trace. Seismicity concentrated near a step in the fault during the Parkfield aftershock sequence [Eaton et al., 1970] and near fault steps in the Imperial Valley [Johnson and Hadley, 1976; Johnson and Hutton, 1982]. The 1987 Superstition Hills earthquake and its aftershocks concentrated at the intersection of two conjugate faults [Magistrale et al., 1989].

Moment release for the Gulf of Alaska events also lies primarily at the intersection of seismicity trends (Figure 6). Since the two nodal planes for these subevents have strikes similar to both trends, these subevents cannot always be unambiguously associated with either trend. The epicenter for event 2 lies at the intersection of an east-west seismicity trend defined by the aftershock sequence of event 1 and its own north-south trending aftershocks. This suggests that for event 2, moment release near the epicenter lies along the north-south trend. Moment release to the south of the epicenter lies near the intersection of the north-south trend and another east-west aftershock trend. Placement 


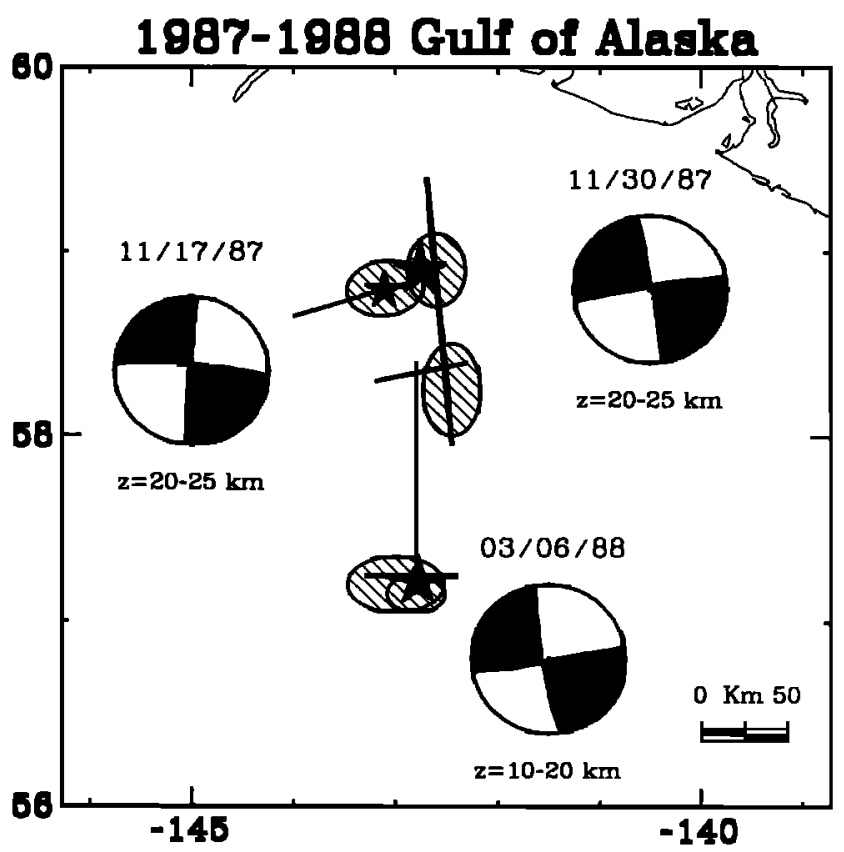

Fig. 6. Summary of source models for the 1987-1988 Gulf of Alaska earthquakes. Lines represent approximate locations of seismic trends (see Figure 2). Stars mark the locally determined epicenters. First motion solutions from J. Lahr (personal communication, 1988) are also shown. Shaded areas mark the regions of maximum moment release for each event.

of moment release along the east-west trend is within the errors of the inversions.

In plan view, regions of large moment release for the Gulf of Alaska earthquakes appear to correspond to regions of high aftershock seismicity. This apparent relationship between moment release and aftershock seismicity contradicts observations by other authors. Comparing slip distribution along a two-dimensional fault plane as determined from inversions of strong motion data to cross sections of aftershock seismicity, several authors have observed that regions of high aftershock seismicity along the fault plane tend to occur outside regions of large slip [Doser and Kanamori, 1986; Hartzell and Heaton, 1986; Wald et al., 1990]. This phenomenon has also been observed with teleseismic data where regions of high moment release have the fewest aftershocks [Schwartz et al., 1989; Hwang et al., 1990]. Since aftershock depths for the Gulf of Alaska earthquakes are undetermined, the aftershock zone and the mainshock rupture zone possibly have different depths. In this case, the relationship between moment release and aftershock seismicity for the Gulf of Alaska events would be similar to that observed for other events.

Intraplate seismicity tends to occur on preexisting weak zones [Sykes, 1978]. Seismicity patterns for the Gulf of Alaska earthquakes correlate with the pattern of magnetic lineations (Figure 1) suggesting that aftershock seismicity may be following preexisting zones of weakness in the crust [Lahr et al., 1988]. A similar relationship has also been observed in the southeastern corner of the Gorda plate [Wilson, 1986]. For the Gulf of Alaska sequence, seismicity approximately follows the axis of magnetic anomaly 13. Aftershock seismicity lies north of a magnetic discontinuity at approximately $57^{\circ}$ [Atwater and Severinghaus, 1989]. Neither the right-lateral offset of seismicity seen in the data nor any other east-west trending features are observed in the magnetics.

While the seismicity patterns are controlled by preexisting weaknesses in the crust, the style of faulting is controlled by the regional stresses. Strike-slip faulting indicates near horizontal minimum and maximum stress directions. As suggested by Lahr et al. [1988], this can occur in between locked and recently slipped zones of the subducting plate. The orientation of the $T$ axes nearly perpendicular to the axis of the Aleutian trench suggests that the Pacific plate is accommodating tensional stresses induced by the 1964 Great Alaskan earthquake. Compressive horizontal stresses along the northern margin are high because of oblique convergence and subduction of the buoyant Yakutat terrane. The orientation of the stress axes inferred from the focal mechanisms of the Gulf of Alaska earthquakes is consistent with this interpretation.

The hypocenters of these events suggest that faulting extended to at least a depth of $25 \mathrm{~km}$. A seismogenic depth of $25 \mathrm{~km}$ is deeper than seen for most strike-slip earthquakes. Seismicity for two large San Andreas earthquakes, the 1986 North Palm Springs, 6.0 $\mathrm{M}_{s}$, and the 1989 Loma Prieta earthquake, 7.1 $M_{s}$ [Given, 1986; Dietz and Ellsworth, 1990] do extend to depths of $20 \mathrm{~km}$, but both mechanisms have appreciable dip-slip components [Jones et al., 1986; Kanamori and Satake, 1990]. More commonly, the seismogenic depth of strike-slip faults in California is approximately $10 \mathrm{~km}$ and no deeper than $15 \mathrm{~km}$. For the Gulf of Alaska earthquakes, a depth of $25 \mathrm{~km}$ does, however, agree with previous studies of oceanic intraplate seismicity. Wiens and Stein [1983, 1984] observed that the maximum depth of seismicity deepens with increasing lithospheric age and appears to be bounded by the $700^{\circ}-800^{\circ} \mathrm{C}$ isotherm. Isotherms derived from a standard plate cooling model [Parsons and Sclater, 1977] suggest that for a crustal age of $35 \mathrm{Ma}$ in the Gulf of Alaska [Atwater and Severinghaus, 1989], the maximum depth of seismicity is approxi. mately $30 \mathrm{~km}$ (Figure 7). The difference in depth reflects the rheological differences between oceanic and continental crust.

To estimate slip and stress drop along the fault, estimates of the fault parameters such as length $l$ and width $w$ are needed. These parameters are usually estimated from the aftershock distributions. For events 1 and 2, aftershock lengths are in good agreement with fault lengths derived from rupture models. Event 3, however, has an aftershock length much longer than that derived from rupture models. Below, $l$ is assumed to be equivalent to the aftershock lengths for events 1 and 2 , but both aftershock length and modeled rupture length are used to bound estimates of slip and stress drop for event 3 .

Fault width is more difficult to estimate since aftershock depths for these events were not determined. Assuming an $l / w$ aspect ratio of 2 would place the largest events well into the upper mantle at depths of 50-70 km. However, the studies of Wiens and Stein [1983, 1984] suggest that seismicity in the region would not extend below $30 \mathrm{~km}$. GLORIA images from the region also indicate that rupture did not reach the surface [Bruns et al., 1989]. Hence the fault width is probably less than $30 \mathrm{~km}$. Here, the fault width is assumed to be approximately $25 \mathrm{~km}$. 


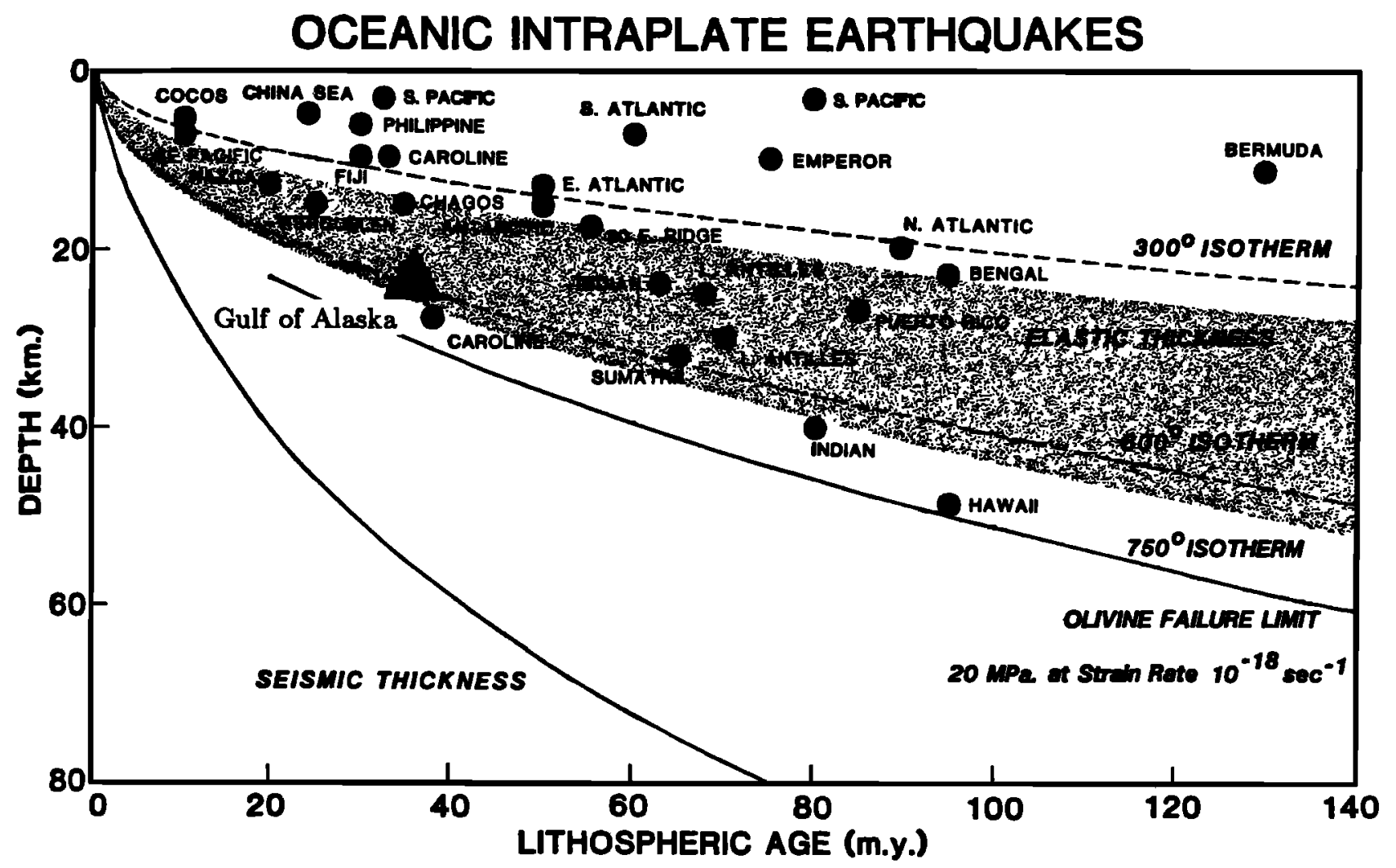

Fig. 7. Intraplate earthquake depths are shown on a depth-age plot of the ocean lithosphere. Isotherms are calculated from a standard lithospheric cooling model [Parsons and Sclater, 1977]. Stippled region denotes the range of estimates of the flexural elastic thickness [Watts et al., 1980]. Seismic thickness is taken from Rayleigh wave dispersion data by Leeds et al. [1974]. The failure limit is the lower limit at which $20 \mathrm{MPa}$ deviatoric stress can be sustained, calculated for a dry olivine rheology [Goetze and Evans, 1979] and a strain rate of $10^{-18} \mathrm{~s}^{-1}$. (After Wiens and Stein [1983].)

Slip is calculated from

$$
u=\frac{M_{0}}{\mu l w}
$$

where $M_{0}$ is moment, $\mu$ is rigidity, $l$ is fault length, and $w$ is fault width. Stress drop for a long-shallow, strike-slip fault is given by Knopoff [1958] as

$$
\Delta \sigma=\frac{(2 \mu \bar{u})}{(\pi w)}
$$

where $\bar{u}$ is the average dislocation. Rigidity and fault width are assumed to be $4.2 \times 10^{11} \mathrm{dyn} / \mathrm{cm}^{2}$ and $25 \mathrm{~km}$, respectively. For event 1 , assuming that $l=40 \mathrm{~km}$ and $M_{o}=7 \times 10^{26}$ dyn $\mathrm{cm}$, then $u=1.7 \mathrm{~m}$ and $\Delta \sigma=$ 18 bars. For event 2 , assuming that $l=140 \mathrm{~km}$ and $M_{0}=7 \times 10^{27}$ dyn $\mathrm{cm}$, then $u=4.8 \mathrm{~m}$ and $\Delta \sigma=$ 51 bars. For event 3 , an aftershock length of $l=110 \mathrm{~km}$ and $M_{o}=4 \times 10^{27}$ dyn $\mathrm{cm}$ gives $u=3.5 \mathrm{~m}$ and $\Delta \sigma=37$ bars. Assuming a much shorter fault length of $l=40 \mathrm{~km}$, then $u=9.5 \mathrm{~m}$ and $\Delta \sigma=102$ bars.

A stress drop of 102 bars for event 3 is high with respect to the stress drop estimated for events 1 and 2 . However, within the errors of the data, both estimates of stress drops for event 3 and the estimate for event 2 are consistent with other intraplate events, while the stress drop for event 1 is more similar to interplate events [Kanamori and Anderson,
1975]. Stress drop varies by up to a factor of 5 between these events.

In comparison to thrust and normal faulting events, these strike-slip events have short durations. Figure 8 plots seismic moment versus source process time for several large earthquakes. Circles representing thrust and normal faulting events fall along an empirical relation found by Furumoto and Nakanishi [1983] where the moment is proportional to the cube of the source process time. Triangles represent four large strike-slip events: the two largest Gulf of Alaska, the 1989 Macquarie Ridge, and the 1976 Guatemala earthquakes [Kanamori and Stewart, 1978; Dziewonski et al., 1989a,b, 1990; Kikuchi and Kanamori, 1991; Satake and Kanamori, 1990].

The Guatemala earthquake falls within the scatter for normal and thrust faulting events. The remainder of the strike-slip events form a separate group whose source process times are much shorter, implying shorter rupture lengths. Rupture lengths for these events are indeed shorter than what is observed for most strike-slip events. These earthquakes, the Gulf of Alaska and the Macquarie Ridge earthquakes, are also large events occurring in oceanic environments. Centroid depths below the Moho indicate that these events ruptured into the upper mantle. The above suggests that oceanic lithosphere has a higher strength than continental lithosphere and results in events with larger moment release per unit area than similar continental events. 


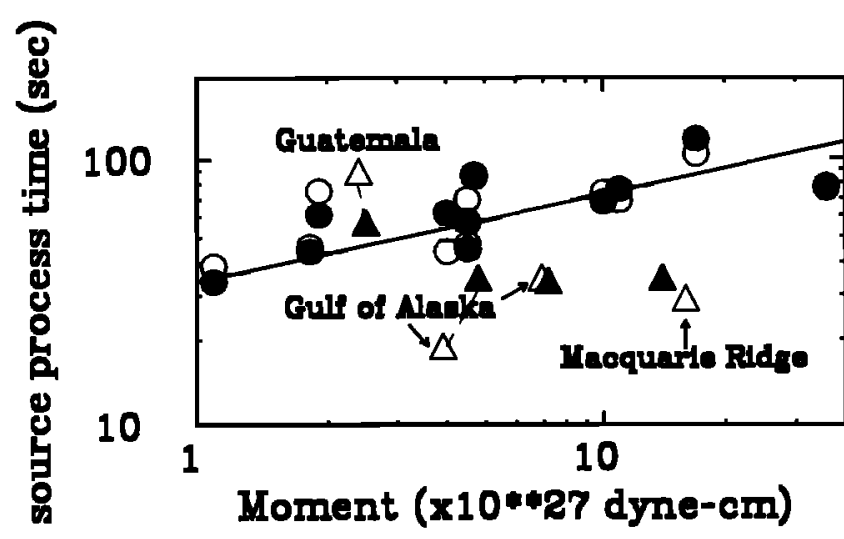

Fig. 8. Relation between seismic moment and source process time for normal and reverse faulting events (circles) and several strike-slip faulting events (triangles). Solid circles indicate source-process times determined from a linear inversion technique, and open circles indicate those determined from Furumoto's method [Zhang and Kanamori, 1988]. Solid triangles show the parameters determined from surface wave modeling, and open triangles show the parameters determined from body wave modeling. References for source parameters for strike-slip events are in the text. The solid line is an empirical relation for low-angle thrust fault earthquakes obtained by Furumoto and Nakanishi [1983], where $M_{o}=2.5 \times 10^{22} \tau^{3}$.

\section{CoNCLUSION}

The 1987-1988 Gulf of Alaska earthquakes are modeled using two different methods: Nábělek [1984, 1985] and Kikuchi and Kanamori [1991]. Ideally, both methods should give the same results. However, differences in the inversion procedure and complexity of the sources results in similar but not identical results for all models. The main difference between the two methods is how the sources are constrained. The former smooths or averages both the moment release distribution and the focal parameters over the duration of the subevent. This is effective for two simple events such as the November 17, 1987, and March 6, 1988, earthquakes. For more complex events, by not constraining a propagation velocity, the latter method allows moment release to occur on portions of the fault plane in which the rupture front has already traveled. This is likely for large events with large faulting dimensions such as the November 30,1987, earthquake. However, trade offs occur between the resolution of the smaller subevents and the loss of smoothness in the time function and stability in the focal mechanism that can give a more satisfactory waveform match.

These earthquakes also illustrate some of the difficulties of modeling strike-slip earthquakes. Modeling suggests that nonplanar crustal structure in the source region for events 1 and 2 results in waveform complexities at shorter periods that are not well-modeled for stations that lie to the north-northeast. The modeling done here also illustrates the sensitivity of the solution to variations in the focal parameters of the subevents. In all events, models using a single focal mechanism could not explain important features in the data. A time varying mechanism was needed to explain both the LP and WWS data. Method
$K$ showed that variations of only $\pm 10^{\circ}$ are necessary and results in a nondouble-couple component typically $<1 \%$, and never more than $8 \%$. In addition, solutions are not unique. All models result in grossly similar solutions that agree with one another within the errors of the inversion. Differences in the models illustrate that different combinations of source time, placement, size, and focal mechanisms can explain the data equally well.

All the models accounted successfully for the LP data. Complex source processes and crustal heterogeneities hindered efforts to model the WWS data robustly for events 1 and 2. However, the main features in the data set were modeled. Event 3 has the simplest waveforms of the earthquakes studied and could be modeled in both bands.

Source parameters agree with previous studies that indicate almost pure, vertical, NS-EW conjugate strike-slip faulting. Centroid depths are well constrained and are deeper than those observed for similar continental interplate events. These events also have shorter rupture lengths and shorter source process times than are observed for most large earthquakes. Similarities in source characteristics to another large, strike-slip, oceanic earthquake, the 1989 Macquarie Ridge earthquake, show that large oceanic strike-slip events can rupture into the upper mantle and can release more moment per unit area than similar crustal events. This may reflect the rheological difference between oceanic and continental lithosphere.

Moment release for these events did not occur smoothly along the entire aftershock length of the faults (Figure 6). Most of the moment release for event 2 is confined to two regions along the fault. A large, lateral extent for event 3 , as implied by the aftershock data, is not supported by the body wave modeling results. In general, most of the moment release occurs near the epicenter and/or regions of intersecting seismic trends. This suggests that regions of structural complexities, fault zone intersections or stepovers, are regions of large moment release and are likely nucleation points for large earthquakes.

\section{APPENDIX A: NOVEMBER 17, 1987}

\section{Models 1 NLP and 1 NWWS}

Event 1 is a relatively simple event. In method $\mathrm{N}$, triangular source elements with duration and rise times of $\tau_{\mathrm{r}}=\tau_{\mathrm{d}}=2 \mathrm{~s}$ are used to model the LP data, while shorter source elements, $\tau_{\mathrm{r}}=\tau_{\mathrm{d}}=1 \mathrm{~s}$, are used to match the higher-frequency content seen in the broader band data. Various single and multiple-source models with source elements described above are initially investigated. Neither single point or propagating point source models could explain both the main arrival and the emergent arrival observed dominantly at the northern stations (Figures A1A5). Hence a two-source model is investigated.

The first subevent constrained to begin at the first arrival time is assumed to initiate at the hypocenter. Since it is modeled as a source with a short duration time (7-8 s), it is assumed not to propagate and is also assumed to have the same centroid depth as the second subevent. The second subevent has a much longer duration time, 10-15 s. For this subevent, different combinations of propagation velocities as well as centroid depths are investigated.

Figure A6a shows the misfits between the observed and calculated seismograms for a centroid depth of $25 \mathrm{~km}$ (justi- 


\section{November 1987}

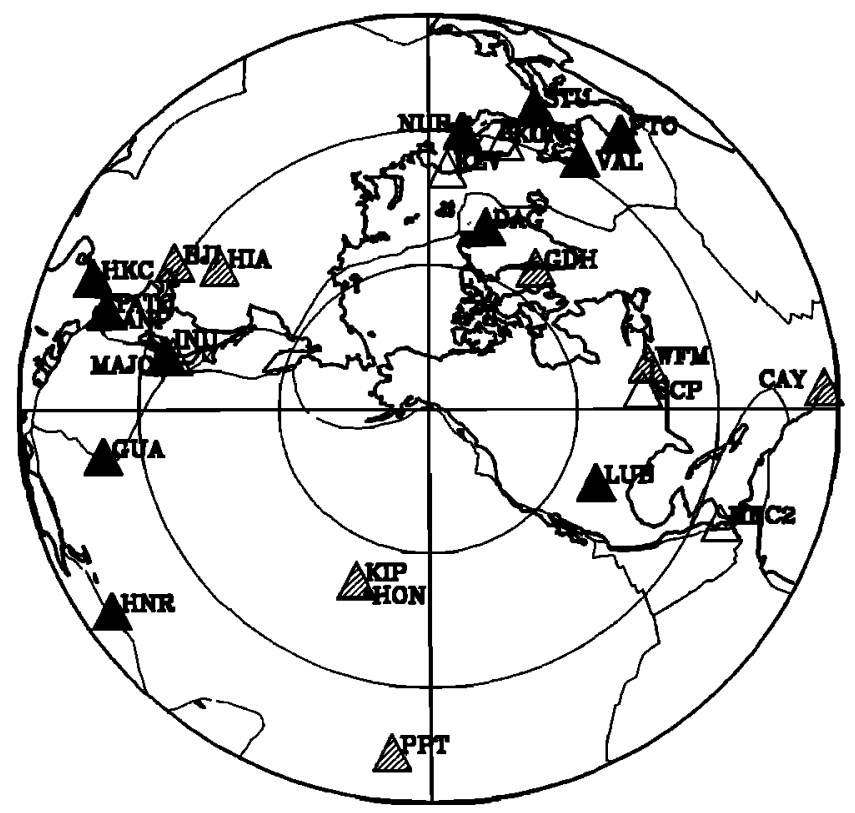

Fig. A1. Equal area projection of the location of the stations used in the inversions with respect to the November 17,1987 , earthquake superimposed on a partial map of the world. Open triangles, stations used only in the LP inversions. Solid triangles, stations used only in the WWS inversions. Hatched triangles, stations used in both the LP and WWS inversions.

fied later) as a function of rupture velocity. For the LP data (dashed line), the errors are roughly independent of velocity for velocities less than $2.5 \mathrm{~km} / \mathrm{s}$ and increase slightly for higher velocities. Over the depth range investigated, errors change little with velocity at any given depth. A change of $1 \mathrm{~km} / \mathrm{s}$ in velocity for a source duration time of $10 \mathrm{~s}$ corresponds to a change in length of $10 \mathrm{~km}$ and is not within the resolution of the LP data. However, the WWS data (solid line) can resolve the propagation velocity to the above accuracy and yields a minimum velocity at $1.0 \mathrm{~km} / \mathrm{s}$ (Figure $\mathrm{A6a}$ ). This velocity reduces the errors in the solution by $20 \%$ over a stationary source $(0 \mathrm{~km} / \mathrm{s})$ and noticeably improves the waveform fit at stations lying toward the west. Hence the main episodes of moment release occurred west of the epicenter but due to the short duration time of the time function and the resolving power of the data, the moment may be distributed up to a distance of $30 \mathrm{~km}$ to the west of the epicenter.

Figure $A 6 b$ shows the misfits between the observed and calculated seismograms as a function of centroid depth for a constant rupture velocity of $1.0 \mathrm{~km} / \mathrm{s}$. For all velocities examined, the errors for both data sets robustly indicate that the best solution lies between 25 and $30 \mathrm{~km}$, with the lowest errors at $25 \mathrm{~km}$. The final models below have a rupture velocity of $1.0 \mathrm{~km} / \mathrm{s}$ and a centroid depth of $25 \mathrm{~km}$.

Figures A2 and A3 show the data, synthetics, and the source-time function for the LP solution: model 1NLP. Model 1NLP fits the observed, long-period waveforms well. The first subevent, 1NLP.1, is a small normal faulting event. Since it overlaps in time with the second subevent (1NLP.2) and has a small amount of moment, it is not well resolved. On the basis of aftershock seismicity, 1NLP.2 has a leftlateral strike-slip mechanism on an east-west trend. The focal mechanism of the second subevent is well resolved at strike $265 \pm 5^{\circ}$, dip $74 \pm 2^{\circ}$, and rake $2 \pm 2^{\circ}$. 1NLP. 2 has roughly 5 times more moment than 1NLP.1. Combined, the total moment is $6.4 \times 10^{26} \mathrm{dyn} \mathrm{cm}$. Source parameters for both subevents are given in Table A1.

Figures A4 and A5 show the results for the WWS data, model 1NWWS. Overall, the synthetics for model 1NWWS fit the observed waveforms well but do not model all of the detail seen in the high-frequency energy. The focal mechanism of the first subevent in the final model is again a poorly resolved normal faulting event. The mechanism for the second subevent is almost identical to that in model $1 N L P$. Its focal parameters are: strike $266 \pm 5^{\circ}, \operatorname{dip} 75 \pm 2^{\circ}$, rake $-2 \pm 2^{\circ}$. Total moment is $8.0 \times 10^{26} \mathrm{dyn} \mathrm{cm}$. Source parameters for both subevents are given in Table $\mathrm{Al}$.

\section{Models $1 K L P$ and $1 K W W S$}

In the inversions using method $K$ for this event, the fault plane spans a distance of $50 \mathrm{~km}$ to the west and $20 \mathrm{~km}$ to the east of the epicenter. The final model LP model, $1 \mathrm{KLP}$, uses a triangular source element where $\tau_{\mathrm{r}}=\tau_{\mathrm{d}}=2 \mathrm{~s}$. This model allows the focal mechanism to vary in time for six iterations. Inversions using a single fixed focal mechanism fail to match the initial arrival at the northern stations and do not match the waveforms at stations to the west [Hwang, 1991]. This indicates that the initial focal mechanism is different from the mechanism of the main subevent and that at least two different focal mechanisms are needed to model this event.

Figures A2 and A3 show all of the data and synthetics for model 1KLP. Overall matches to the waveforms are good. $P$ waveform shapes in the beginning of the record for KONO and GDH to the north are not as well fit as KEV but are better fit than other single and multiple source models investigated. A slightly longer duration of the synthetics than the data and the mismatch in the amplitudes at stations TATO and MAJO suggests that westerly rupture propagation could improve the fit.

In model $1 \mathrm{KLP}$, the largest and best resolved subevent accounts for over $50 \%$ of the total moment. It lies at a depth of $20 \mathrm{~km}$ and at a distance of $20 \mathrm{~km}$ east of the epicenter. Most of the subevents lie east of the epicenter between a depth of 10-20 km (see Table A1). One subevent does lie to the west, but it accounts for less than $10 \%$ of the total moment. Comparison with 1NLP suggests that the LP data can resolve moment release only within a horizontal distance of $\pm 20 \mathrm{~km}$ about the epicenter. The best double-couple sum has a scalar moment of $8.4 \times 10^{26} \mathrm{dyn} \mathrm{cm}$ with a very small nondouble-couple component $(<1 \%)$. A complete description of all subevents is given in Table A1.

The WWS data are modeled using the same source and model parameterization as above. The correlation functions from the first iteration have one well isolated peak (Figure A7), but at least two subevents with different focal mechanisms are still needed to model the data [ $H w a n g$, 1991]. Figures A4 and A5 show the data and synthetics for the final WWS model, $1 \mathrm{KWWS}$, allowing the focal mechanism to vary for four iterations. Stations with relatively simple $P$ waveforms are well matched, but the details in 


\section{November 1987 $P$ waves}
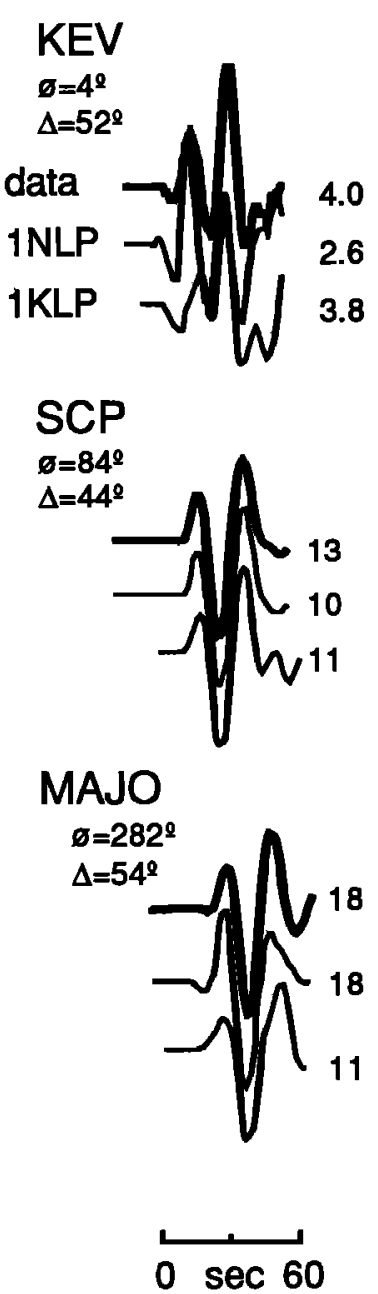
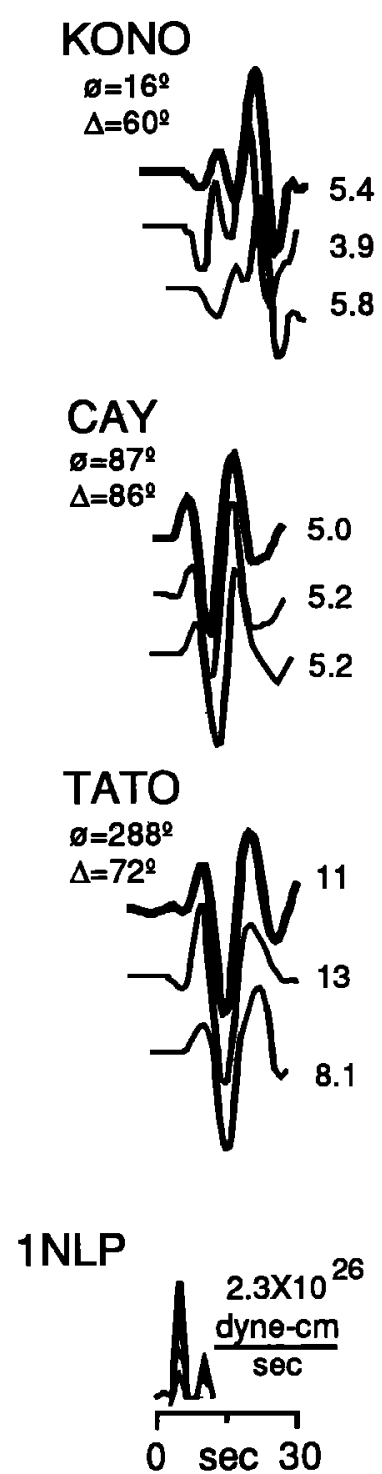

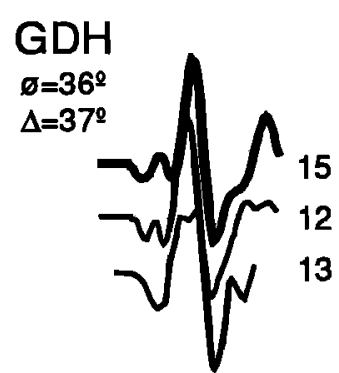

HDC

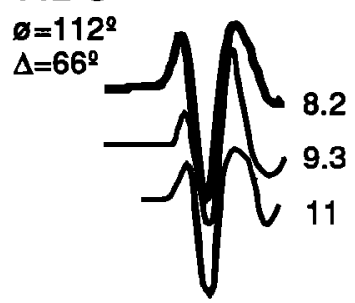

BJI

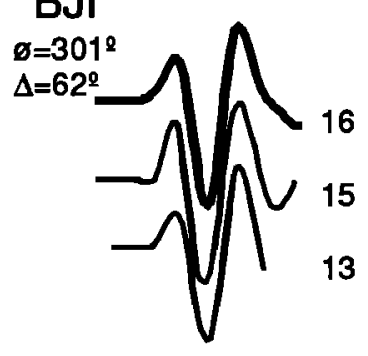

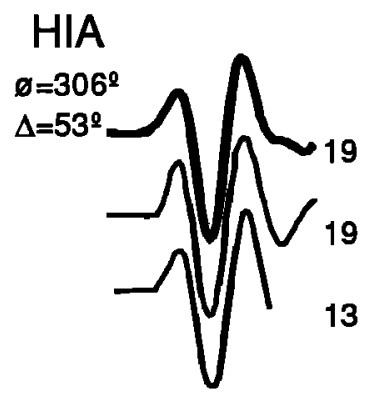
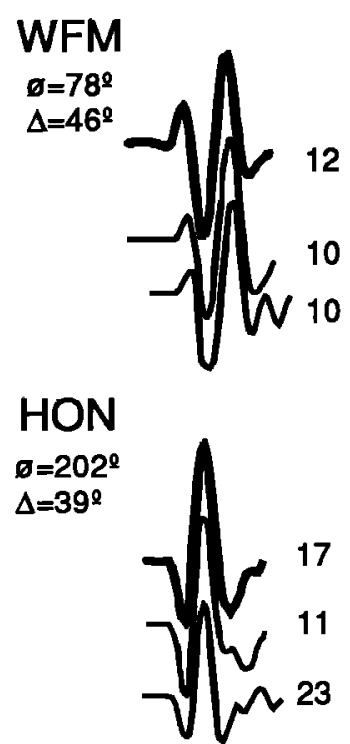

Fig. A2. Observed (heavy lines) and synthetic LP $P$ wave seismograms for model 1NLP and model 1KLP. Distance and azimuth are shown under the station name. Maximum amplitude in microns is shown to the right of each trace. The source time functions are shown at the bottom. For model 1NLP, the unhatched regions represent the percentage of moment contributed by 1NLP.1 and hatched regions by 1NLP.2. Source parameters are given in Table A1.

the data, especially for stations to the NNE, are difficult to model.

In model 1KWWS, the largest subevent lies $10 \mathrm{~km}$ to the west of the epicenter at a depth of $20 \mathrm{~km}$. Its correlation functions (Figure A7) indicate that its along-strike position is not as well resolved as its timing and suggest that the position of this subevent can be up to $20 \mathrm{~km}$ to the west or $10 \mathrm{~km}$ to the east of the epicenter. The shallower dip of the first subevent as compared to the LP results (see Table A1) is a robust feature (Figure A7). Focal mechanisms for the individual subevents are consistently left-lateral, strike-slip on an E-W trending fault plane. Most of the subevents occur at a depth of $20 \mathrm{~km}$ and are distributed to the west of the epicenter (see Table A1). The best double-couple sum has a scalar moment of $6.3 \times 10^{26} \mathrm{dyn} \mathrm{cm}$ with a small nondouble-couple component $(<1 \%)$. A complete description of all subevents is given in Table A1.

\section{APPENDIX B: NOVEMPER 30, 1987}

\section{Models 2NLP and $2 N W W S$}

Inspection of the long-period and broadband waveforms indicates that event 2 is a complex event (Figures B1B5). As seen on the broadband records, this event begins 


\section{November 1987 $\mathrm{SH}$ waves}
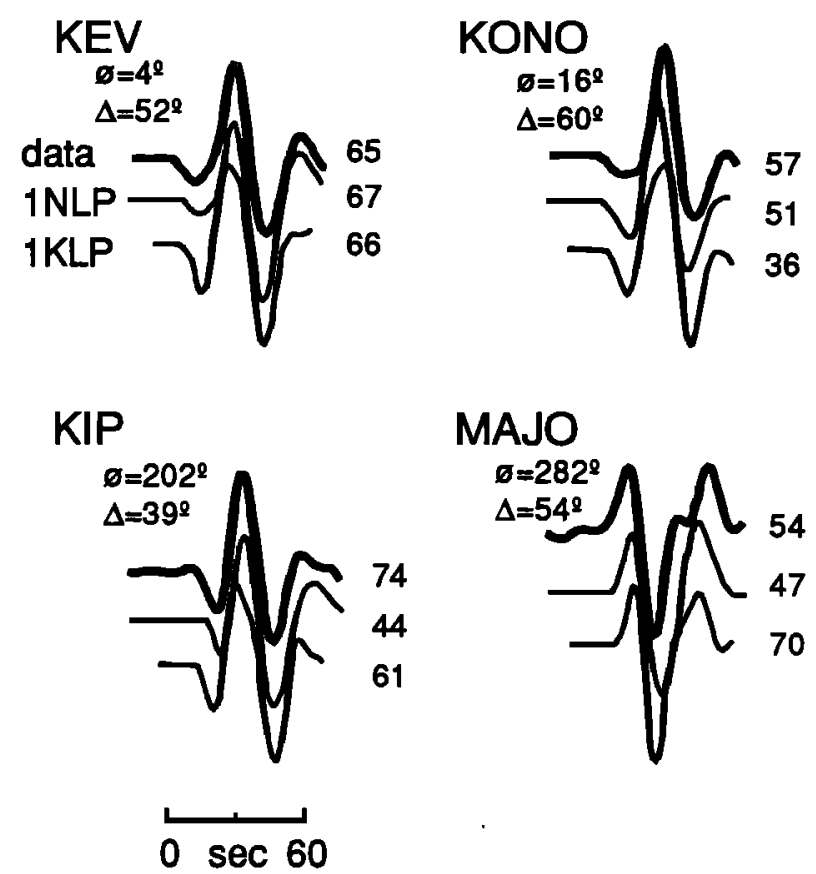

MAJO

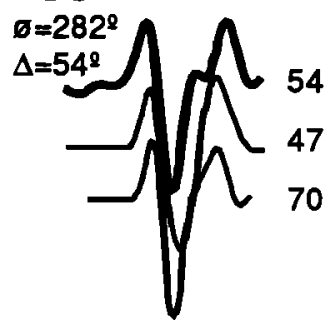

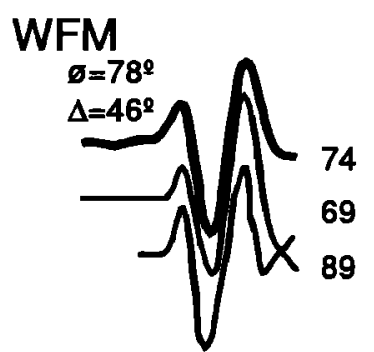

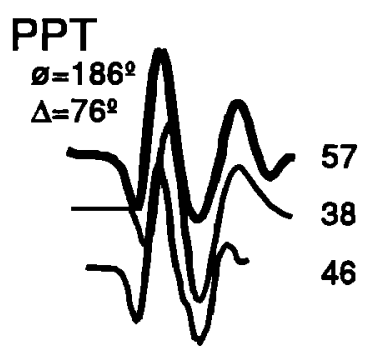

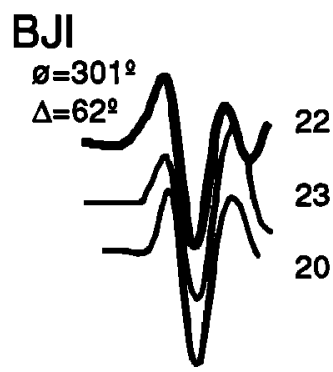

Fig. A3. Observed (heavy lines) and synthetic LP $S H$ wave seismograms for model 1 NLP and model 1KLP. Symbols are explained in Figure A2.

emergently with most of the energy not arriving until $15 \mathrm{~s}$ after the first arrival. In method $\mathrm{N}$, the models are parameterized with multiple subevents using triangular-source elements with $\tau_{\mathrm{r}}=\tau_{\mathrm{d}}=2 \mathrm{~s}$ for both the LP and WWS data. Initial attempts to model this event with 2 subevents were unsuccessful in modeling the first $15 \mathrm{~s}$ of the waveform. Hence at least three subevents are needed to model the data. This agrees with the analysis of Deschamps et al. [1988]. The first subevent is modeled as a point source of short duration, constrained to start at the first arrival time and located at the epicenter. Both point and propagating point sources are examined for subevents 2 and 3 . As suggested by the aftershock seismicity, the fault length initially investigated extends $40 \mathrm{~km}$ to the north and $100 \mathrm{~km}$ to the south of the epicenter.

The LP data are initially used to investigate different source models. Various combinations of multiple and propagating point sources were tried, including bilateral rupture and unilateral rupture models. The best parameterization is a three-point source model where subevent 1 is fixed at the epicenter and the positions of subevents 2 and 3 are varied over the length of the fault.

Figure B6 contours the normalized rms errors for a depth of $25 \mathrm{~km}$ (justified later). The results of this modeling are not robust. The LP errors clearly show that moment release occurred both north and south of the epicenter but the locations are not well constrained. The WWS data are thus used to further constrain the positions of the subevents. As suggested by the LP model errors, only positions to the south of the epicenter are investigated for subevent 2 and to the north for subevent 3 for the WWS models. Since the trend of the errors for many of the solutions was still decreasing at a distance of $40 \mathrm{~km}$, additional northerly positions were also investigated. Figure B7 shows the errors for the WWS models. The least error for a centroid depth of $25 \mathrm{~km}$ occurs when subevent 3 is $60 \mathrm{~km}$ north of the epicenter and subevent 2 is $70 \mathrm{~km}$ south of the epicenter (Figure $B 7 a)$. Figure B7b shows that the depth is well constrained at $25 \mathrm{~km}$ for the above source positions and, in general, is the best depth for most of the three-point source models investigated.

The WWS data indicate source positions at $60 \mathrm{~km}$ north and $70 \mathrm{~km}$ south for subevents 3 and 2 , respectively. For the above position of subevent 2 , the LP data prefer that subevent 3 lies between 10 and $40 \mathrm{~km}$ north (Figure B7a). The position of subevent 3 determined from the WWS data is much farther north than the position preferred by the LP data. A position of subevent 3 at $60 \mathrm{~km}$ north for the LP data results in a solution whose synthetics are inconsistent with the WWS data. As determined from the errors in the LP data, the best position for subevent 3 lies at $20 \mathrm{~km}$ north. This solution provides a better overall match to the LP waveform, and the resulting source-time function is consistent with the WWS results. The difference in the LP and WWS locations is significant and may indicate that subevent 3 cannot be so simply parameterized.

Figure B2 and B3 show the data, synthetics, and the source-time function for the LP solution: model 2 NLP. In 


\section{November 1987 \\ $P$ waves}
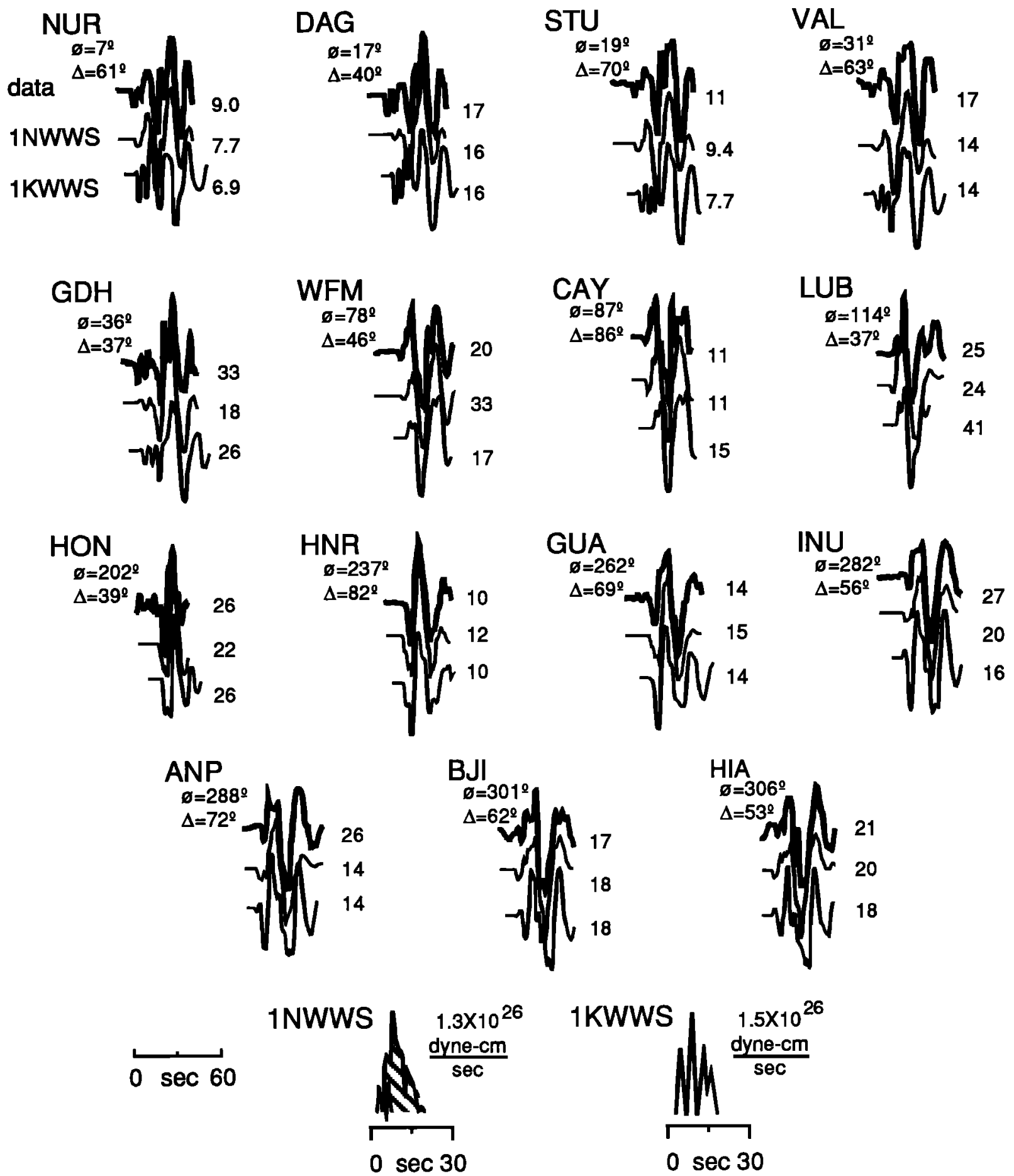

Fig. A4. Observed (heavy lines) and synthetic WWS $P$ wave seismograms for model 1 NWWS and model 1 KLWWS. For model 1NWWS, the unhatched regions represent the percentage of moment contributed by 1NWWS.1 and hatched regions by 1NWWS.2. Symbols are explained in Figure A2.

general, the synthetics fit the data quite well. Assuming that slip took place on a north-south trend, all three subevents have strike-slip mechanisms. However, the mechanism for subevent 1 has an opposite sense of motion than the two larger subevents. Subevent 1 does not show up clearly as a separate arrival at all stations and is also not reliable because of its relatively small size. The focal mechanism for subevent 2, 2NLP.2, which lies south of the epi- 


\section{November 1987 $\mathrm{SH}$ waves}
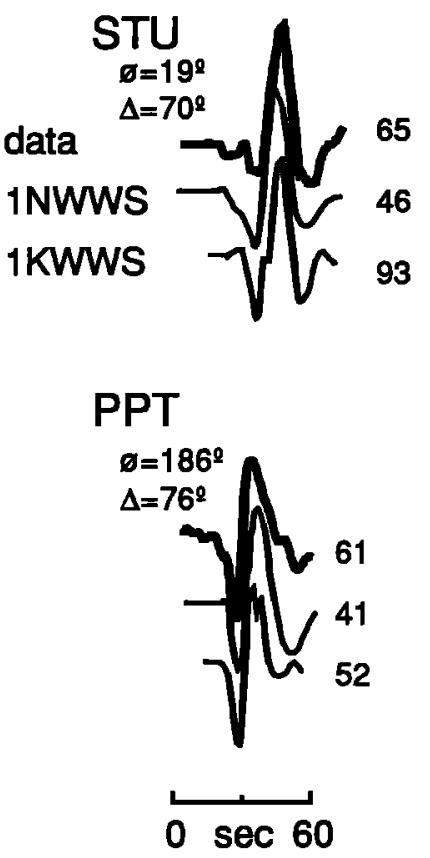
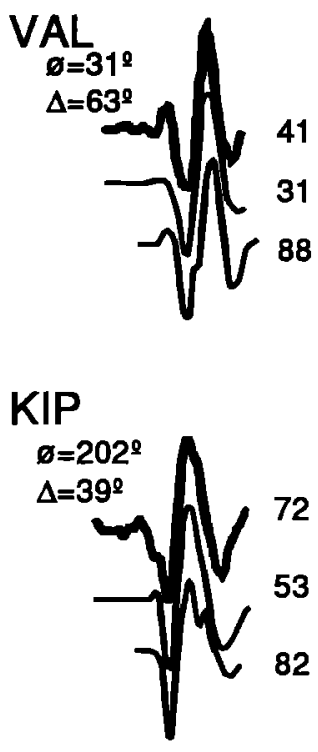
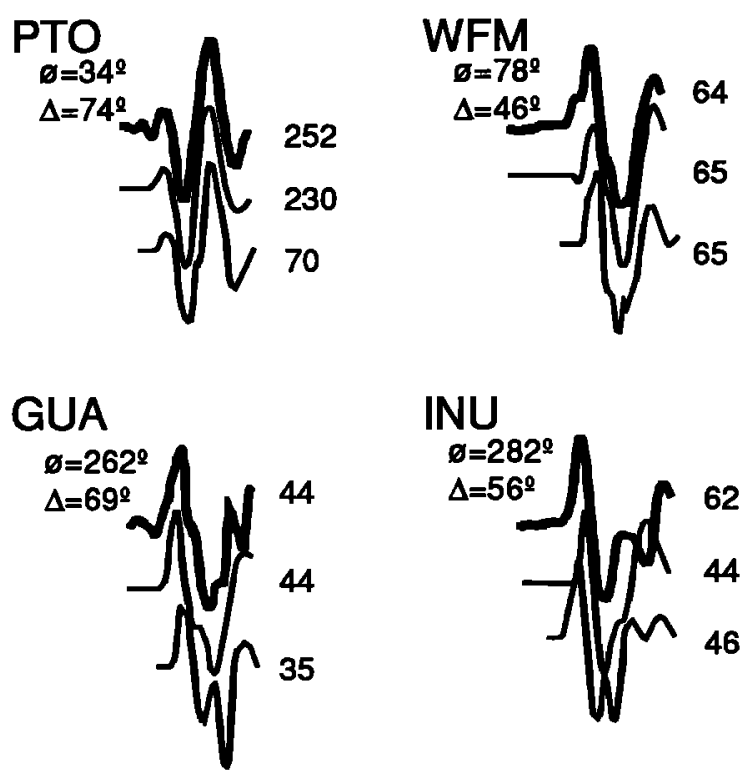

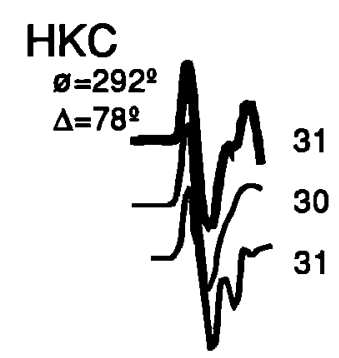

Fig. A5. Observed (heavy lines) and synthetic WWS $S H$ wave seismograms for model 1 NWWS and model 1KLWWS. Symbols are explained in Figure A2.

\section{November 1987}

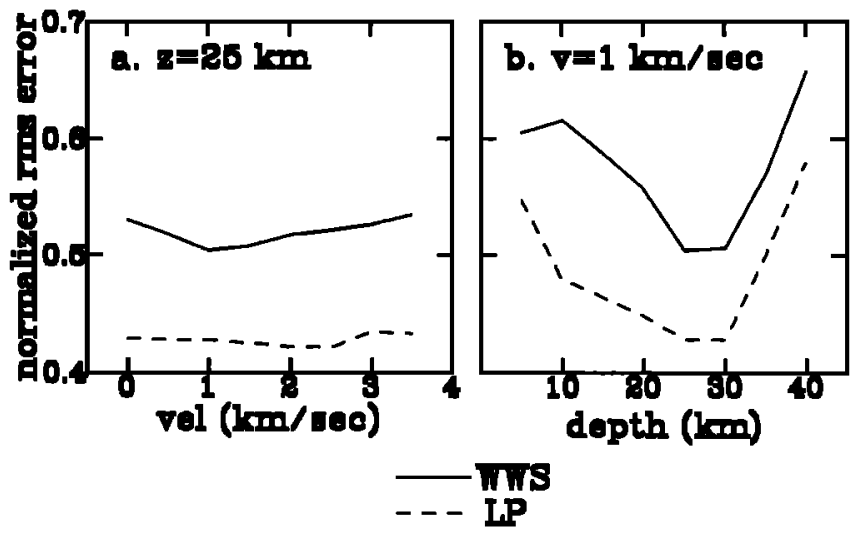

Fig. A6. Data misfits for the LP (dashed line) and WWS (solid line) data for method N. Plotted are the normalized rms errors versus: (a) velocity for a fixed centroid depth of $25 \mathrm{~km}$, and (b) centroid depth for a fixed velocity of $1 \mathrm{~km} / \mathrm{s}$. center, is rotated more westerly than the other two mechanisms and dips near vertically. It contrasts with subevent 3 , 2NLP.3, which lies to the north and has a roughly northsouth strike and dips to the west. 2NLP.2 has approximately the same moment as 2NLP.3. Total moment for this model is $7.7 \times 10^{27} \mathrm{dyn} \mathrm{cm}$. The source parameters for all subevents are given in Table $\mathrm{B} 1$.

For a depth of $25 \mathrm{~km}$ and source positions of subevent 2 to the south and subevent 3 to the north, estimates of the error in the focal parameters vary. Formal errors indicate that the focal mechanism for 2NLP.2 is better constrained than 2NLP.3. The different models suggest that for 2NLP.2, the strike and dip may be underestimated by $5^{\circ}$ and $10^{\circ}$, respectively, and rake may vary by $\pm 5^{\circ}$. For 2 NLP.3, both the strike and dip may be overestimated by $5^{\circ}$ and the rake by $10^{\circ}$. This error range suggests that the two subevents may not be so different.

Figures B4 and B5 show the WWS results for model 2NWWS. The general shape of the waveforms is well modeled. However, not all of the features are satisfactorily 
TABLE A1. November 17, 1987, Summary of Source Parameters for Event 1

\begin{tabular}{|c|c|c|c|c|c|c|c|c|c|c|}
\hline Model & $\begin{array}{c}\text { Strike, } \\
\text { deg }\end{array}$ & $\begin{array}{l}\text { Dip, } \\
\text { deg }\end{array}$ & $\begin{array}{c}\text { Rake, } \\
\text { deg }\end{array}$ & $\begin{array}{c}\text { Depth, } \\
\text { km }\end{array}$ & $\begin{array}{c}\text { Delay, } \\
\text { s }\end{array}$ & $\begin{array}{l}\text { Velocity, } \\
\mathrm{km} / \mathrm{s}\end{array}$ & $\begin{array}{c}\text { Distance, } \\
\mathbf{k m}\end{array}$ & $\begin{array}{c}\text { Azimuth, } \\
\text { deg }\end{array}$ & $\begin{array}{r}\text { Mom } \\
\text { dyn cm }\end{array}$ & $10^{26}$ \\
\hline$\overline{1 N L P .1}$ & 184 & 44 & -73 & $\overline{25}$ & 0 & & $\mathbf{0}$ & $\mathbf{0}$ & 1.1 & \\
\hline 1NLP.2 & 265 & 74 & 2 & 25 & 4 & 1.0 & & & 5.3 & $(6.4)$ \\
\hline 1NWWS.1 & 160 & 40 & -62 & 25 & 0 & & $\mathbf{0}$ & $\mathbf{0}$ & 1.3 & \\
\hline 1NWWS.2 & 266 & 75 & -2 & 25 & 2.3 & 1.0 & & & 6.7 & $(\mathbf{8 . 0 )}$ \\
\hline \multirow[t]{6}{*}{ 1KLP } & $\begin{array}{l}260 \\
262\end{array}$ & $\begin{array}{l}84 \\
85\end{array}$ & $\begin{array}{l}-8 \\
-3\end{array}$ & $\begin{array}{l}20 \\
20\end{array}$ & 9 & $3.5^{\#}$ & 20 & 90 & $\begin{array}{l}8.4 \\
5.5\end{array}$ & \\
\hline & 234 & 63 & -32 & 10 & 5 & & 20 & 90 & 1.5 & \\
\hline & 228 & 86 & 190 & 10 & 13 & & 10 & 90 & 1.2 & \\
\hline & 253 & 76 & -10 & 20 & 15 & & 40 & 270 & 1.0 & \\
\hline & 283 & 55 & 74 & 40 & 15 & & 20 & 90 & 0.5 & \\
\hline & 252 & 89 & 2 & 20 & 4 & & 10 & 90 & 0.9 & (10.6) \\
\hline \multirow[t]{5}{*}{ 1KWWS } & 275 & 78 & 0 & 20 & & $3.5^{\#}$ & & & 6.3 & \\
\hline & 273 & 66 & 1 & 20 & 7.5 & & 10 & 270 & 3.1 & \\
\hline & 219 & 87 & 190 & 10 & 11.5 & & 40 & 270 & 1.9 & \\
\hline & 250 & 82 & 2 & 20 & 4.0 & & 10 & 270 & 2.1 & \\
\hline & 278 & 86 & 8 & 20 & 15.0 & & 0 & 270 & 1.4 & (8.5) \\
\hline
\end{tabular}

See text. For models N, source parameters for all subevents are given. Total moment is given in parentheses. For models $\mathrm{K}$, the first row gives the source parameters for the best double-couple sum of the focal mechanisms of the subevents solved for in the inversion. Listed after this in their inversion order are the source parameters for each subevent. The sum of their moment is given in parentheses.

* Fixed.

\# Maximum rupture velocity.

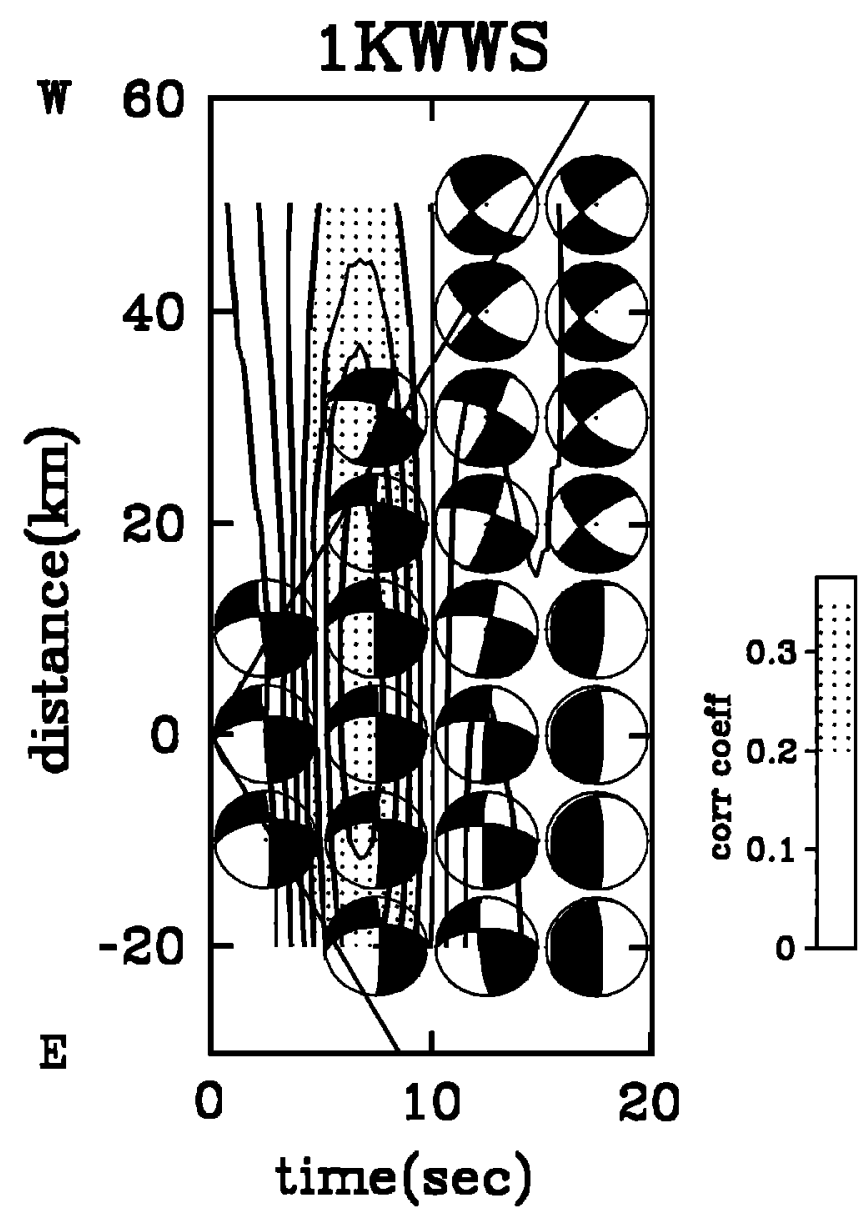

Fig. A7. 1KWSS. Plotted are the contours of the correlation coefficients at intervals of 0.05 and the corresponding best fit double-couple focal mechanisms in the $\tau-l$ plane for the first iteration. The lower hemisphere equal-area focal mechanisms are plotted at time intervals of $5 \mathrm{~s}$ at each grid point along strike. The solid lines radiating away from a distance of $0 \mathrm{~km}$ and a time of $0 \mathrm{~s}$ shows the envelope of the maximum allowable rupture velocity.

\section{November 1987}

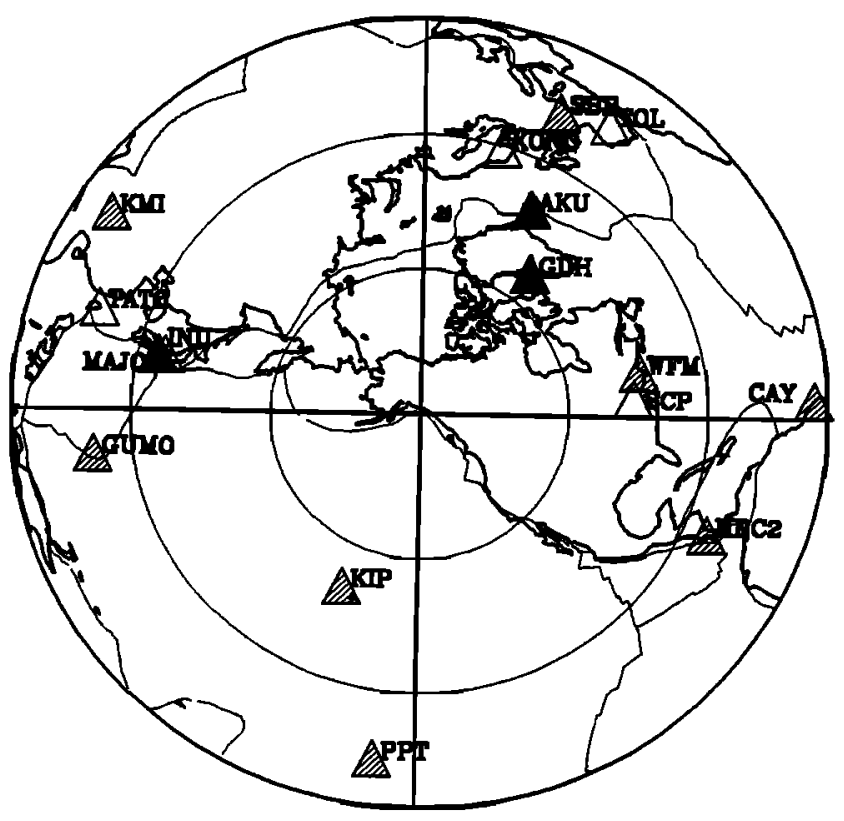

Fig. B1. Equal area projection of the location of the stations used in the inversions with respect to the November 30,1987 , earthquake superimposed on a partial map of the world. Open triangles, stations used only in the LP inversions. Solid triangles, stations used only in the WWS inversions. Hatched triangles, stations used in both the LP and WWS inversions.

explained. This can be due to several causes. First, least squares inversion techniques tend to match the largest power in the data. Hence good fits to smaller moment carrying sources tend to be sacrificed to fit the larger sources. Second, waveforms are poorly fit if arrivals are not coherent enough between stations. Lastly, both receiver and source crustal structure can have an important effect on the observed waveforms. 


\section{November 1987}

$P$ waves
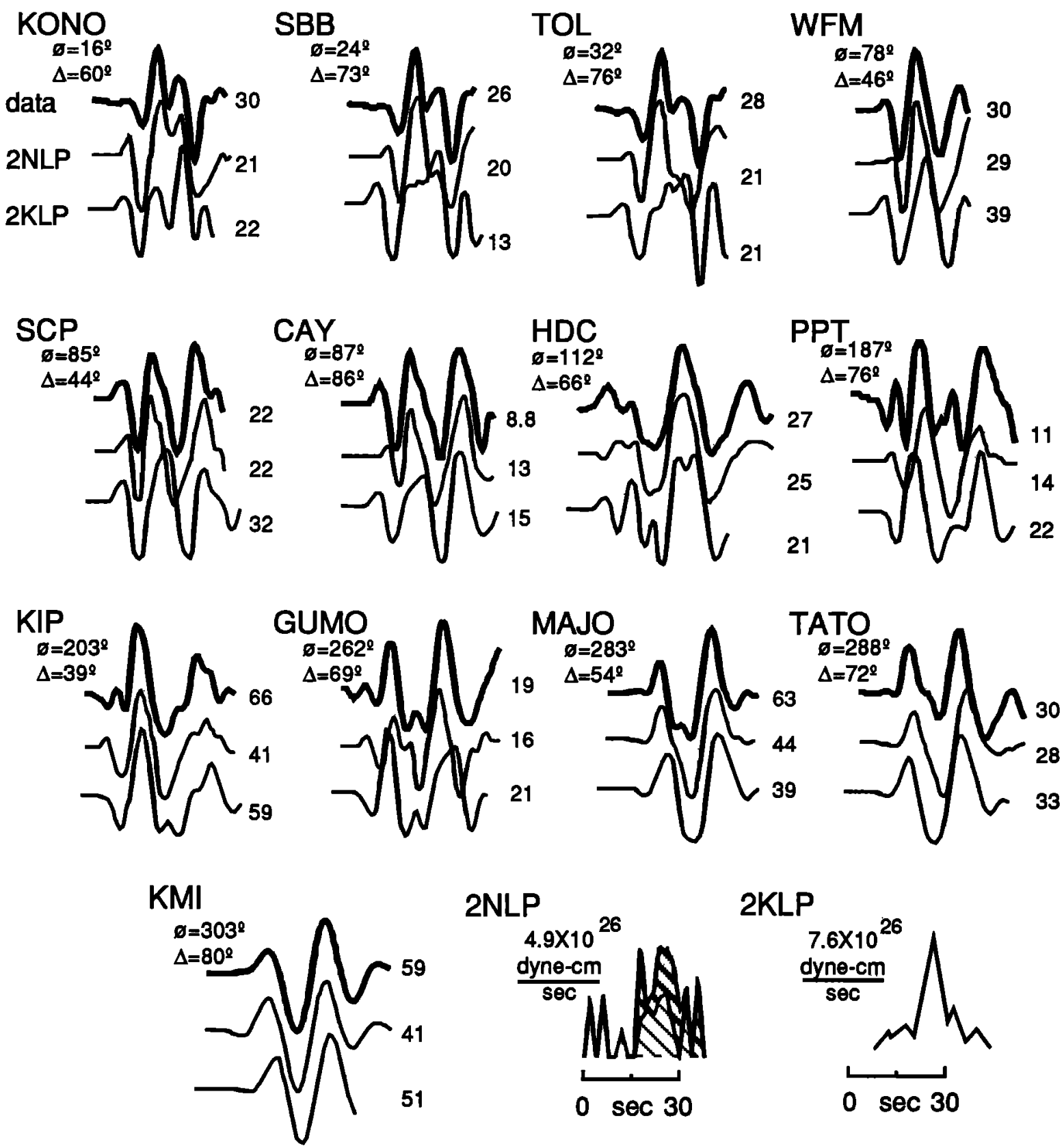

\section{$0 \sec 60$}

Fig. B2. Observed (heavy lines) and synthetic LP $P$ wave seismograms for model 2 NLP and model 2KLP. Distance and azimuth are shown under the station name. Amplitude in microns is shown to the left of each trace. The source time functions are shown at the bottom. For model 2NLP, the unhatched regions represent the percentage of moment contributed by 2 NLP.1, light hatched regions represent that contributed by 2 NLP.2, and dark hatched regions represent that contributed by 2 NLP.3. Source parameters are given in Table B1.

For many stations, the first arrivals are late. Several stations (SBB, AKU, HDC, and GUMO) lie very near $P$ wave nodes for the first subevent, 2NWWS.1, contributing to the low amplitudes and lateness of the first arrival in the synthetics. Misfits to the data may also indicate that the source at this bandwidth is more complex than a simple, three-point source model.

Slightly less than half of the stations (CAY, PPT, KIP, GUMO, INU) are located on islands. Local crustal structure and water depth vary greatly between these stations. 


\section{November 1987 $\mathrm{SH}$ waves}
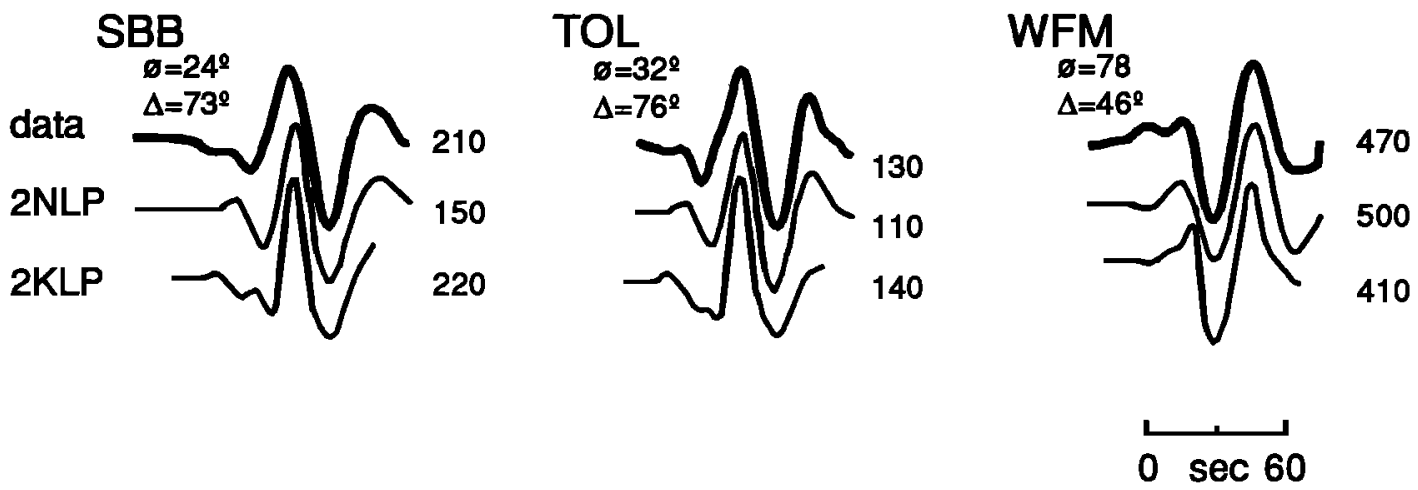

Fig. B3. Observed (heavy lines) and synthetic LP $S H$ wave seismograms for model 2 NLP and model 2KLP. Symbols are explained in Figure B2.

$P$ waves from strike-slip type earthquakes, however, are more sensitive to source structure [Langston, 1977]. Both the November 17 and 30, 1987 earthquakes occurred near the base of the continental slope. In this region, both water depth and crustal structure change rapidly toward the NNE as oceanic crust abuts the Yakutat terrane [von Huene et al., 1979]. Such near-source heterogeneity will affect the complexity of the signal. This may explain why the WWS waveforms at stations to the NNE are relatively complex compared to the remainder of the data set for both events. The third event of March 6, 1988, modeled below, lies well away from this boundary. Waveform data for that event do not show any substantial difference in complexity with azimuth. This suggests that the boundary between the $\mathrm{Pa}$ cific plate and the Yakutat terrane affects the coherency of the signal and the ability to model all arrivals.

Focal mechanisms for the three subevents indicate strikeslip motion. The mechanism for 2 NWWS.1 has an opposite sense of motion than the two larger subevents. The poor fit of the waveforms to the first arrivals indicates that its focal mechanism is unreliable. The focal mechanisms for 2NWWS.2 and 2NWWS.3 are modeled as right-lateral strike-slip events on a north-south trending fault. The strike of 2NWWS.2 trends NNW-SSE and dips vertically, while the strike of 2 NWWS. 3 trends NNESSW with an easterly dip. 2NWWS.2 is roughly twice as large as 2NWWS.3. Total moment for this model is $8.2 \times 10^{27}$ dyn $\mathrm{cm}$. Source paraméters for all subevents are given in Table $B 1$.

Formal errors again indicate that 2NWWS.2 is better resolved than 2 NWWS.3 and that the focal mechanisms for 2NWWS are better resolved than for 2NLP. For a depth of $25 \mathrm{~km}$ and distances for subevents 2 and 3 similar to the final model, estimates of error in the focal parameters vary. For 2 NWWS.2, the strike and dip are perhaps underestimated by $10^{\circ}$, and rake is overestimated by $10^{\circ}$. For 2NWWS.3, the strike and rake may be overestimated by $10^{\circ}$ and dip underestimated by $10^{\circ}$. Again, these error bounds would bring the focal mechanisms of 2 NWWS.2 and 2NWWS.3 in better agreement with one another.

\section{Models 2KLP and $2 K W W S$}

In the inversion using method $K$, the fault plane dimensions are comparable to those searched in the previous models and extends $40 \mathrm{~km}$ to the north and $100 \mathrm{~km}$ to the south of the epicenter. Systematic variation of the time function shows that the source element that best matches the rise times in the waveform is a triangular time function where $\tau_{\mathrm{r}}=\tau_{\mathrm{d}}=5 \mathrm{~s}$.

Modeling suggests that multiple subevents with different mechanisms are needed to explain the data [Hwang, 1991]. The final model, 2KLP, allows the focal mechanism to vary in time for five iterations. Figures B2 and B3 show the data and synthetics for model 2KLP. The overall match to the waveforms is good. Moment release does not begin for $8 \mathrm{~s}$; hence several stations (KIP, GUMO, PPT) are noticeably ill-matched in the beginning of the waveform: their signal being too small to be modeled.

In model 2KLP, the largest subevent is located at a depth of $20 \mathrm{~km}$ and at a distance of $90 \mathrm{~km}$ south of the epicenter. This subevent accounts for $55 \%$ of the total moment release. Two of the subevents are located north of the epicenter at a distance of $20-30 \mathrm{~km}$ and account for approximately $12 \%$ of the total moment release. The best double-couple sum of the five subevents composing the solution has a scalar moment of $5.3 \times 10^{27}$ dyn cm with an $8 \%$ nondouble-couple component. Both the best double couple solutions and the source parameters for all subevents are given in Table B1.

Inversion of the WWS data required source elements with a faster rise time and shorter duration, $\tau_{\mathrm{r}}=\tau_{\mathrm{d}}=2 \mathrm{~s}$, to match the data. A large rupture velocity of $10 \mathrm{~km} / \mathrm{s}$ is allowed but in the final model, the solution has no subevents exceeding a speed of $3.5 \mathrm{~km} / \mathrm{s}$. The best correlation for the initial iteration occurs at $25 \mathrm{~s}$ at a position $40 \mathrm{~km}$ south of the epicenter (Figure $\mathrm{B} 8$ ). The along strike position is 


\section{November 1987 $P$ waves}
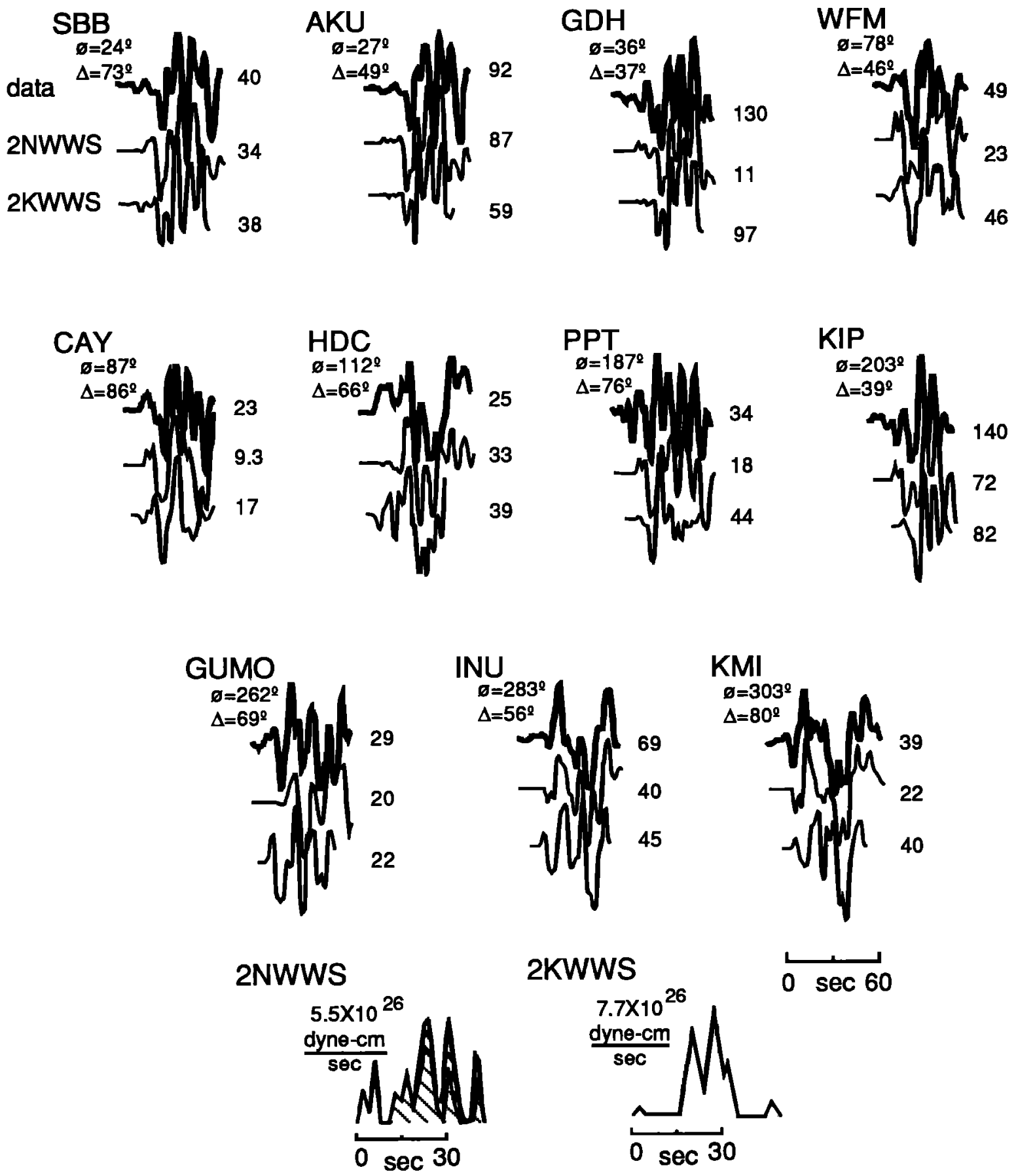

Fig. B4. Observed (heavy lines) and synthetic WWS $P$ wave seismograms for model 2 NWWS and model $2 \mathrm{KWWS}$. The unhatched regions represent the percentage of moment contributed by 2 NWWS.1, light hatched regions represent that contributed by 2NWWS.2, and dark hatched regions represent that contributed by 2NWWS.3. Symbols are explained in Figure B2.

not as well resolved as the timing of this subevent. The extremely elongated contours of the correlation coefficient indicate that best position is not really significantly better than most other positions along the fault plane. One reason why the resolution may be poor is that subevents of comparable size may also be occurring during this time interval along other portions of the fault.

The corresponding best fit focal mechanisms are similar to those for the LP data. They are relatively constant in the along-strike directions but change rapidly to mech- 


\section{November 1987 $\mathrm{SH}$ waves}
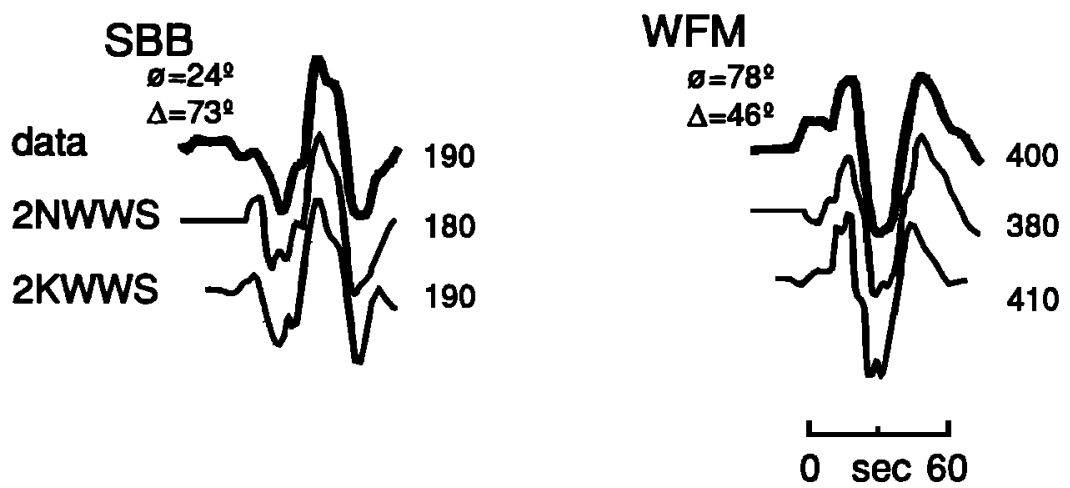

Fig. B5. Observed (heavy lines) and synthetic WWS $S H$ wave seismograms for model $2 N W W S$ and model 2KWWS. Symbols are explained in Figure B2.

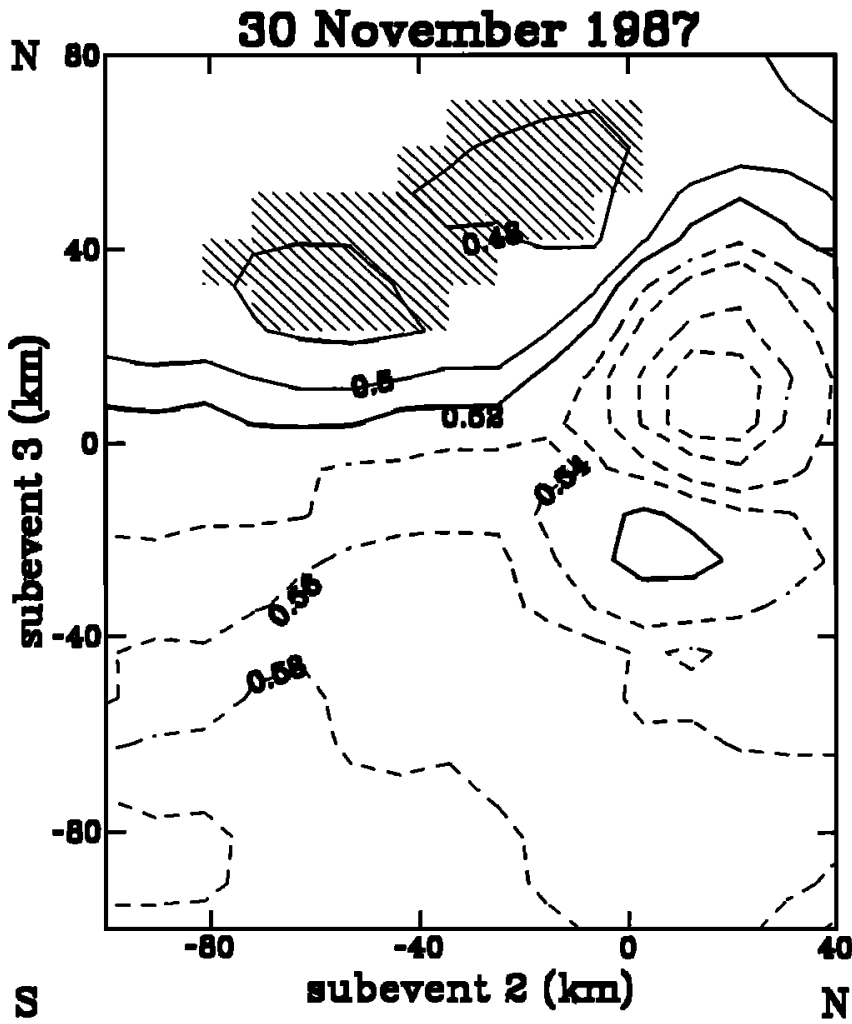

Fig. B6. Data misfits for the LP data for method N. Contoured are the normalized rms errors for the along strike distance of subevent 3 versus subevent 2 for a fixed centroid depth of $25 \mathrm{~km}$.

anisms opposite to the best-fit mechanism outside an approximately 15-8-long time window.

The WWS data are much more complex than the LP data and are also modeled using a time varying focal mechanism. Figures B4 and B5 show the data and synthetics for model 2KWWS. Table B1 gives the best double-couple
30 November 1987

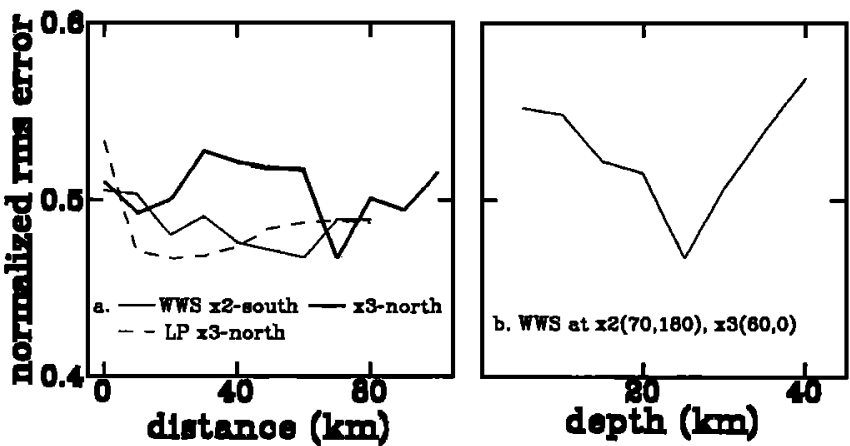

Fig. 7. Intraplate earthquake depths are shown on a depthage plot of the ocean lithosphere. Isotherms are calculated from a standard lithospheric cooling model [Parsons and Sclater, 1977]. Stippled region denotes the range of estimates of the flexural elastic thickness [Watts et al., 1980]. Seismic thickness is taken from Rayleigh wave dispersion data by Leeds et al. [1974]. The failure limit is the lower limit at which $20 \mathrm{MPa}$ deviatoric stress can be sustained, calculated for a dry olivine rheology [Goetze and Evans, 1979] and a strain rate of $10^{-18} \mathrm{~s}^{-1}$. (After Wiens and Stein [1983].)

sum of the 10 subevents comprising the solution as well as the source parameters for each subevent. Overall, the features in the waveforms are adequately modeled. Similar to 2NWWS, many features are still not explained (see above discussion). Moment release begins late at $11 \mathrm{~s}$; hence the beginning portion of the waveforms is again not modeled.

In model $2 \mathrm{KWWS}$, most of the moment release occurs between 20 and $60 \mathrm{~km}$ south of the epicenter, with the two largest subevents at 40 and $60 \mathrm{~km}$ south at a depth of $20 \mathrm{~km}$. Essentially, no moment release occurs to the north. The best double-couple has a scalar moment of $5.6 \times 10^{27} \mathrm{dyn} \mathrm{cm}$ with a $4 \%$ nondouble-couple component. 
TABLE B1. November 30, 1987, Summary of Source Parameters for Event 2

\begin{tabular}{|c|c|c|c|c|c|c|c|c|c|c|}
\hline Model & $\begin{array}{c}\text { Strike, } \\
\text { deg }\end{array}$ & $\begin{array}{l}\text { Dip, } \\
\text { deg }\end{array}$ & $\begin{array}{c}\text { Rake, } \\
\text { deg }\end{array}$ & $\begin{array}{c}\text { Depth, } \\
\text { km }\end{array}$ & $\begin{array}{c}\text { Delay, } \\
\mathbf{s}\end{array}$ & $\begin{array}{l}\text { Velocity, } \\
\mathrm{km} / \mathrm{s}\end{array}$ & $\begin{array}{c}\text { Distance, } \\
\mathbf{k m}\end{array}$ & $\begin{array}{l}\text { Azimuth, } \\
\text { deg }\end{array}$ & $\begin{array}{l}\text { Mome } \\
\text { dyn cm }\end{array}$ & $\begin{array}{l}\text { ent, } \\
\times 10^{27}\end{array}$ \\
\hline$\overline{2 N L P .1}$ & 2 & 82 & 4 & 25 & $\mathbf{0}$ & & $\mathbf{0}$ & 0 & 1.0 & \\
\hline 2NLP.2 & 160 & 92 & 168 & 25 & 10 & & 70 & 180 & 3.2 & \\
\hline 2NLP.3 & 188 & 76 & 208 & 25 & 16 & & 20 & 0 & 3.5 & $(7.7)$ \\
\hline 2NWWS.1 & 182 & 99 & 6 & 25 & $\mathbf{0}$ & & $\mathbf{0}$ & 0 & 1.1 & \\
\hline 2NWWS.2 & 171 & 90 & 188 & 25 & 11 & & 70 & 180 & 4.6 & \\
\hline 2NWWS.3 & 188 & 98 & 187 & 25 & 20 & & 60 & 0 & 2.5 & $(8.2)$ \\
\hline \multirow[t]{6}{*}{ 2KLP } & 177 & 97 & 173 & 20 & & \# & & & 5.3 & \\
\hline & 0 & 86 & 181 & 20 & 22 & & 90 & 180 & 3.8 & \\
\hline & 335 & 79 & -140 & 40 & 14 & & 30 & 180 & 0.6 & \\
\hline & 80 & 42 & 105 & 50 & 38 & & 30 & 0 & 0.4 & \\
\hline & 131 & 90 & 138 & 30 & 8 & & 20 & 0 & 0.4 & \\
\hline & 6 & 86 & 180 & 30 & 29 & & 60 & 180 & 1.4 & (6.6) \\
\hline \multirow[t]{11}{*}{ 2KWWS } & 180 & 94 & 179 & 20 & & \# & & & 5.6 & \\
\hline & 184 & 90 & 179 & 20 & 25 & & 40 & 180 & 2.2 & \\
\hline & 3 & 83 & 181 & 20 & 18 & & 60 & 180 & 1.5 & \\
\hline & 0 & 87 & 177 & 20 & 30.2 & & 10 & 180 & 1.1 & \\
\hline & 351 & 45 & 213 & 40 & 18.8 & & 60 & 180 & 0.4 & \\
\hline & 180 & 81 & 183 & 20 & 20.8 & & 60 & 180 & 0.6 & \\
\hline & 359 & 76 & 185 & 30 & 28.5 & & 90 & 180 & 0.5 & \\
\hline & 16 & 78 & 52 & 10 & 1.8 & & 0 & 180 & 0.2 & \\
\hline & 358 & 86 & -6 & 20 & 43.8 & & 80 & 180 & 0.4 & \\
\hline & 341 & 82 & 182 & 40 & 19.2 & & 40 & 0 & 0.2 & \\
\hline & 134 & 82 & -133 & 30 & 24.2 & & 40 & 0 & 0.2 & (7.1) \\
\hline
\end{tabular}

See text and Table A1.

" Fixed.

\# See text.
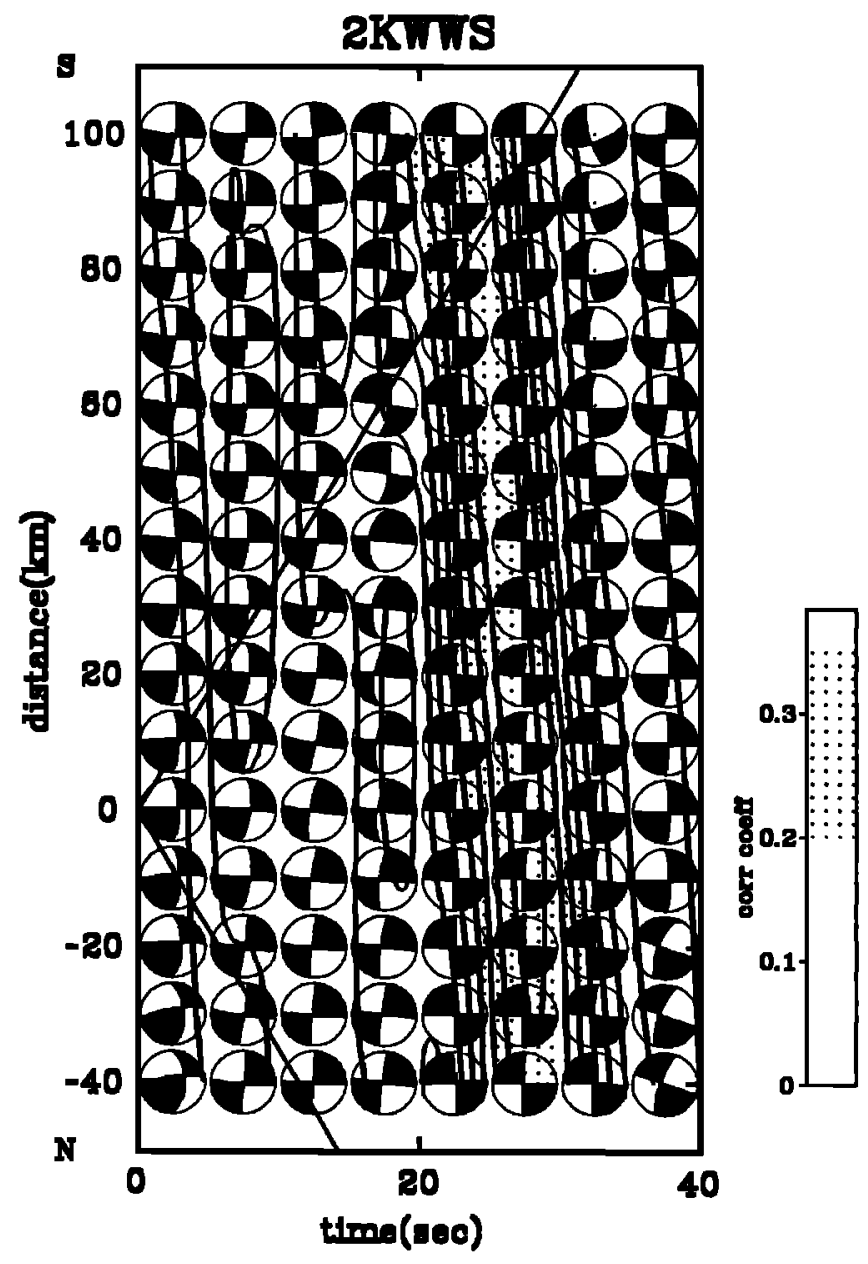

Fig. B8. 2KWWS. Layout is described in Figure A7.

\section{APPENDIX C: March 6,1988}

\section{Models $3 N L P$ and $3 N W W S$}

Inspection of the waveforms suggests that event 3 is the simplest event in the sequence (Figures C1-C5). Unlike the first two events, no precursory arrival is evident on the LP records. The WWS records show a small arrival at the beginning of many records that has too small an amplitude to model. For method $\mathrm{N}$, models using triangular source elements with $\tau_{\mathrm{r}}=\tau_{\mathrm{d}}=2 \mathrm{~s}$ best fit the data. Different combinations of point and propagating point sources lying either to the north or west of the epicenter were investigated. In general, the error in the fit to the data becomes larger if most of the moment release is forced to lie away from the epicentral region. For all models, source depths between $5-40 \mathrm{~km}$ and rupture velocities between $0.0-5.0 \mathrm{~km} / \mathrm{s}$ are systematically investigated.

The best parameterization consists of one point source propagating to the west and one point source at the epicenter. Figures $\mathrm{C} 6 a$ and $\mathrm{C} 6 \mathrm{~b}$ show the misfits between the observed and calculated LP seismograms. As shown in Figure $\mathrm{C} 6 b$, the best centroid depth for a fixed rupture velocity of $3.5 \mathrm{~km} / \mathrm{s}$ lies near $15-20 \mathrm{~km}$. For a centroid depth of $15 \mathrm{~km}$, the rupture velocity is not well-resolved. The least error solution occurs at $3.5 \mathrm{~km} / \mathrm{s}$, but a velocity between $2.0-4.0 \mathrm{~km} / \mathrm{s}$ is within the acceptable error range (Figure C6a). The WWS data constrain the centroid depth at $15 \mathrm{~km}$ for a rupture velocity of $3.5 \mathrm{~km} / \mathrm{s}$. Rupture velocity is not as well constrained: the best solution is at a velocity of $3.5 \mathrm{~km} / \mathrm{s}$ but can be as low as $2.0 \mathrm{~km} / \mathrm{s}$ (Figure C6c).

The preferred LP model, model 3NLP, begins with subevent 3 NLP. 1 propagating towards the west at a velocity of $3.5 \mathrm{~km} / \mathrm{s}$ at a depth of $15 \mathrm{~km}$. Subevent 2, 3NLP.2, 


\section{March 1988}

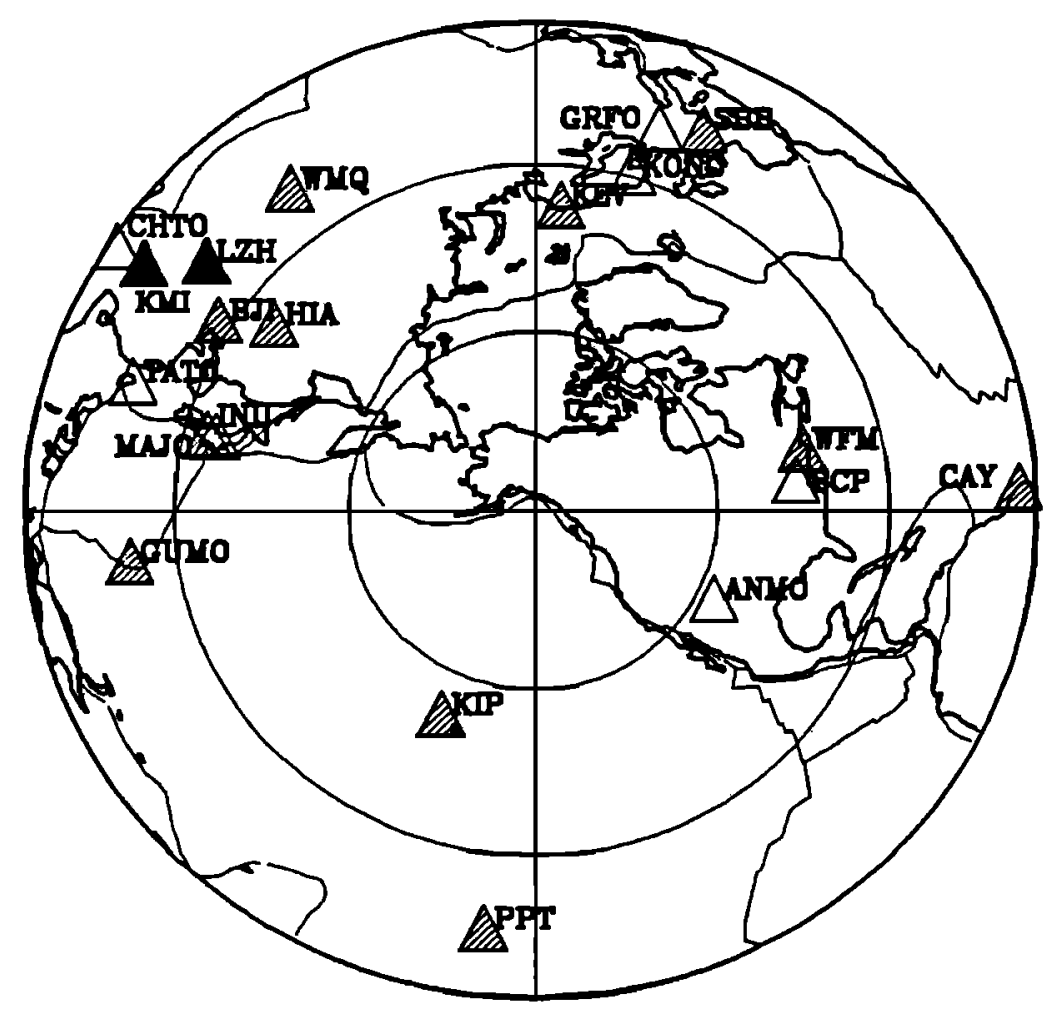

Fig. C1. Equal area projection of the location of the stations used in the inversions with respect to the March 6, 1988, earthquake superimposed on a partial map of the world. Open triangles, stations used only in the LP inversions. Solid triangles, stations used only in the WWS inversions. Hatched triangles, stations used in both the LP and WWS inversions.

begins at $13 \mathrm{~s}$ and is modeled as a point source at a depth of $15 \mathrm{~km}$ below the epicenter. It has roughly half the moment as 3NLP.1. The two largest moment releasing episodes occur at a distance of approximately 21 and $35 \mathrm{~km}$ from the epicenter and at an azimuth of $268^{\circ}$. In this model, moment release extends to a distance of $42 \mathrm{~km}$. A distance as short as $24 \mathrm{~km}$ corresponding to a rupture velocity of $2 \mathrm{~km} / \mathrm{s}$ is also within the error range of the model. Total moment for this model is $4.9 \times 10^{27} \mathrm{dyn} \mathrm{cm}$. See Table C1.

Figures $\mathrm{C} 2$ and $\mathrm{C} 3$ show the data, synthetics, and the source-time function for model 3NLP. The synthetics are an excellent fit to the data. One exception is the $P$ wave at station GUMO. GUMO lies near the node of the first subevent, which causes the onset of the event in the synthetic to have a very low amplitude.

The focal mechanisms of the two subevents are very similar. Both subevents have strike-slip focal mechanisms with moderate dips. 3NLP.1 is left-lateral rupturing toward the west along a steeply, southerly dipping fault plane. 3NLP.2 is located at the epicenter, which lies at the junction of both the westerly and northerly aftershock seismicity trends. Hence the sense of motion is ambiguous. For the range of velocities investigated at a fixed centroid depth of $15 \mathrm{~km}$, the estimates of the focal parameters are stable. For the east-west nodal plane for 3NLP.1, the estimates of the strike vary by $\pm 10^{\circ}$, the dip may be underestimated by $3^{\circ}$, and the rake overestimated by $5^{\circ}$. For the north-south nodal plane for 3NLP.2, the estimates of the strike vary by $\pm 10^{\circ}$, dip $\pm 2^{\circ}$, and rake $\pm 2^{\circ}$.

The final WWS model, model $3 \mathrm{NWWS}$, is in good agreement with model 3NLP. Figures $\mathrm{C4}$ and $\mathrm{C5}$ show the results for model 3 NWWS. The synthetics match most of the features in the data quite well. The focal mechanism for subevent $1,3 \mathrm{NWWS.1}$, is in good agreement with 3NLP.1. The estimated error for the focal parameters is $\pm 1^{\circ}$. Subevent $2,3 N W W S .2$, is rotated clockwise with respect to 3NWWS.1, and its focal mechanism is not as wellresolved. The strike may be overestimated by $5^{\circ}$, dip by $3^{\circ}$ and the slip may vary by $\pm 1^{\circ}$. 3NWWS.1 again has roughly twice the moment as 3 NWWS.2, which begins at $13 \mathrm{~s}$. Moment release associated with 3NWWS.1 occurs between distances of 7 and $42 \mathrm{~km}$ from the epicenter at an azimuth of $268^{\circ}$ and has a fairly smooth source time function. Again for a smaller rupture velocity of $2 \mathrm{~km} / \mathrm{s}$, a distance range of 4-24 km is also within the error range of the models. Total moment release for this model is $4.4 \times 10^{27} \mathrm{dyn} \mathrm{cm}$. See Table C1.

\section{Models $3 K L P$ and $3 K W W S$}

In the inversions using method $\mathrm{K}$, the fault plane dimensions are comparable to those investigated with method $\mathrm{N}$. Moment release along both a north-south trend extending $110 \mathrm{~km}$ to the north and $20 \mathrm{~km}$ to the south and an east- 


\section{March 1988 $P$ waves}
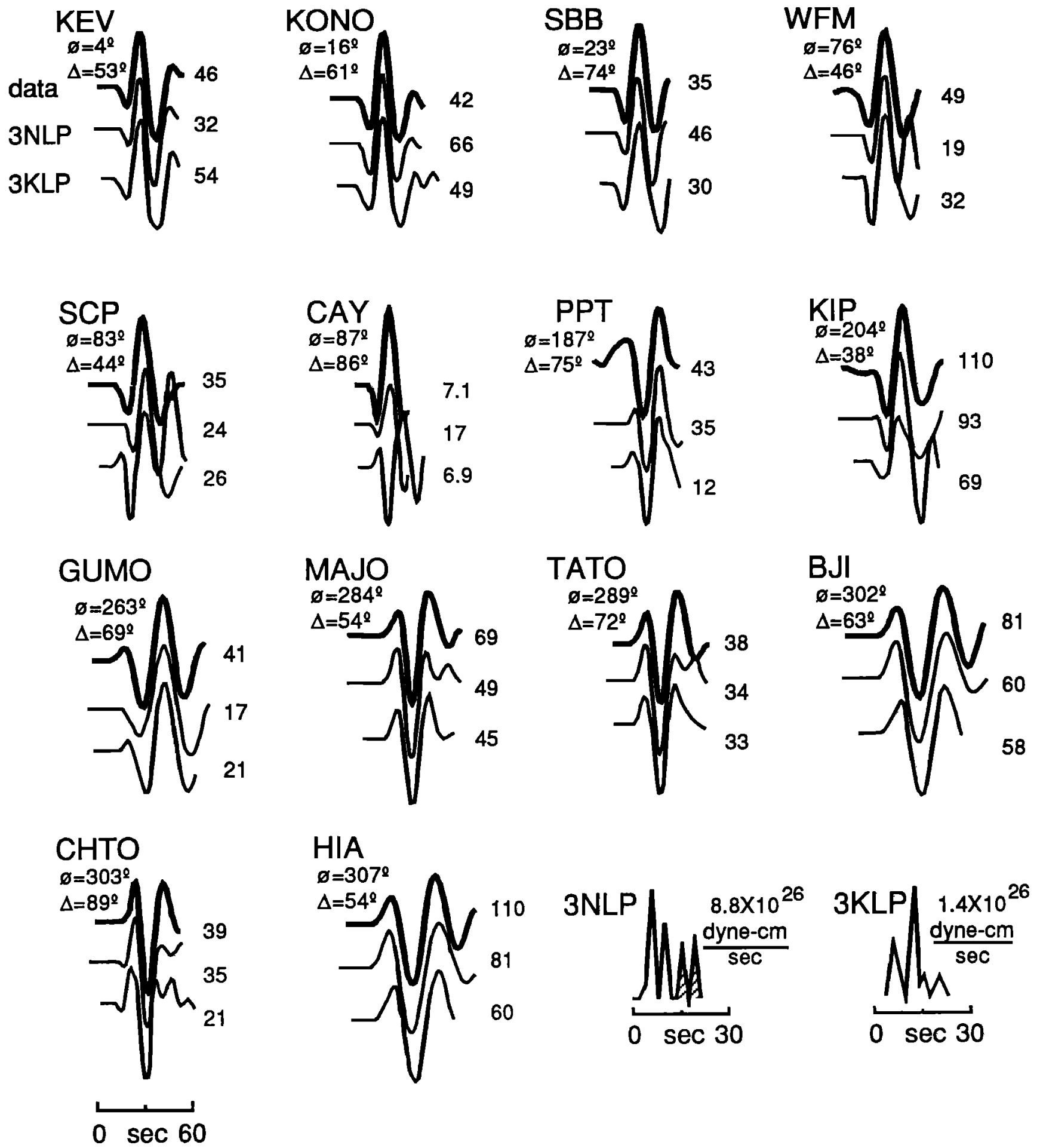

Fig. C2. Observed (heavy lines) and synthetic LP $P$ wave seismograms for model 3NLP and model 3KLP. Distance and azimuth are shown under the station name. Amplitude in microns is shown to the left of each trace. The source time functions are shown at the bottom. For model 3NLP, the unhatched regions represent the percentage of moment contributed by 3NLP.1 and hatched regions by 3NLP.2. Source parameters are given in Table C1. 


\section{March 1988 $\mathrm{SH}$ waves}
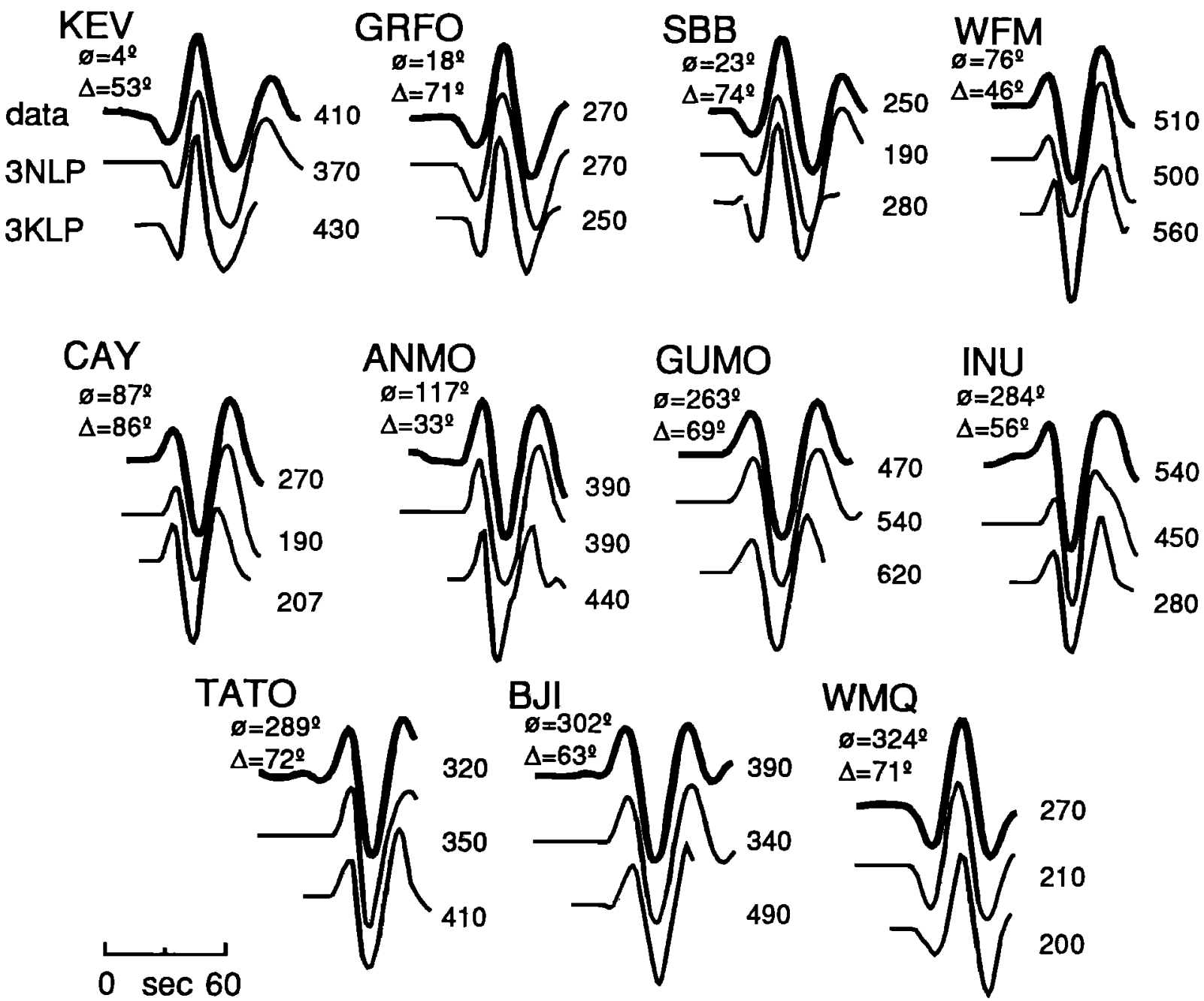

Fig. C3. Observed (heavy lines) and synthetic LP $S H$ wave seismograms for model 3 NLP and model 3KLP. Symbols are explained in Figure C2.

west trend extending $60 \mathrm{~km}$ to the west and $10 \mathrm{~km}$ to the east is investigated. Systematic variation of the time function showed that the source element that best matches the rise times in the data had $\tau_{\mathrm{r}}=\tau_{\mathrm{d}}=2 \mathrm{~s}$. For the LP data, the north-south fault plane resulted in the lowest overall errors.

Model 3KLP allows the focal mechanism to vary in time for five iterations. A single focal mechanism could not explain the data [Hwang, 1991]. Figures C2 and C3 show the data and synthetics for model 3KLP. The $S H$ wave amplitudes are well matched and so are the $P$ wave amplitudes for the northern stations. However, amplitudes of the $P$ wave synthetics for the remainder of the stations are consistently low with respect to the data. Additional iterations contain little moment and hence do not significantly improve the solution.
In model 3KLP, most of the moment release occurs at a depth of $20 \mathrm{~km}$ and within a distance of $20 \mathrm{~km}$ of the epicenter. Modeling the rupture along an east-west fault plane gives results consistent with the above interpretation. In model $3 \mathrm{KLP}$, only one subevent accounting for a little over $10 \%$ of the total moment occurred at a greater distance: $40 \mathrm{~km}$ to the north. The best double-couple sum has a scalar moment of $3.9 \times 10^{27} \mathrm{dyn} \mathrm{cm}$ with a very small nondouble-couple component $(<1 \%)$. A complete description of all subevents is given in Table C1.

The WWS data are modeled using a source element of longer duration, $\tau_{\mathrm{r}}=2 \mathrm{~s}$ and $\tau_{\mathrm{d}}=4 \mathrm{~s}$. The duration of a simple, triangular source element, $\tau_{\mathrm{r}}=\tau_{\mathrm{d}}=2 \mathrm{~s}$, is too short to match the data. The fault plane of the preferred model, model $3 \mathrm{KWWS}$, trends east-west. The correlation functions of the initial iteration and their corresponding 


\section{March 1988 $P$ waves}
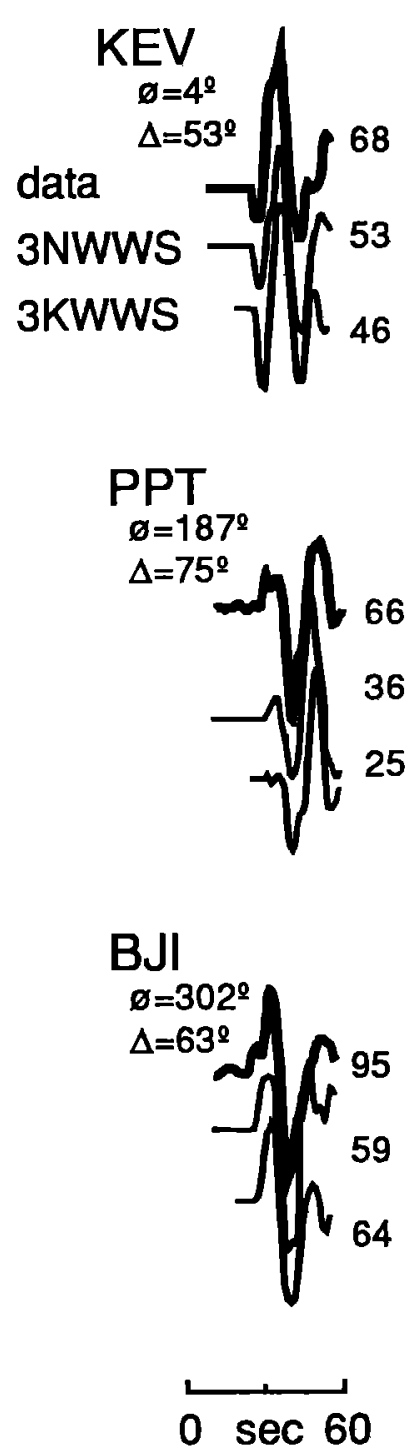
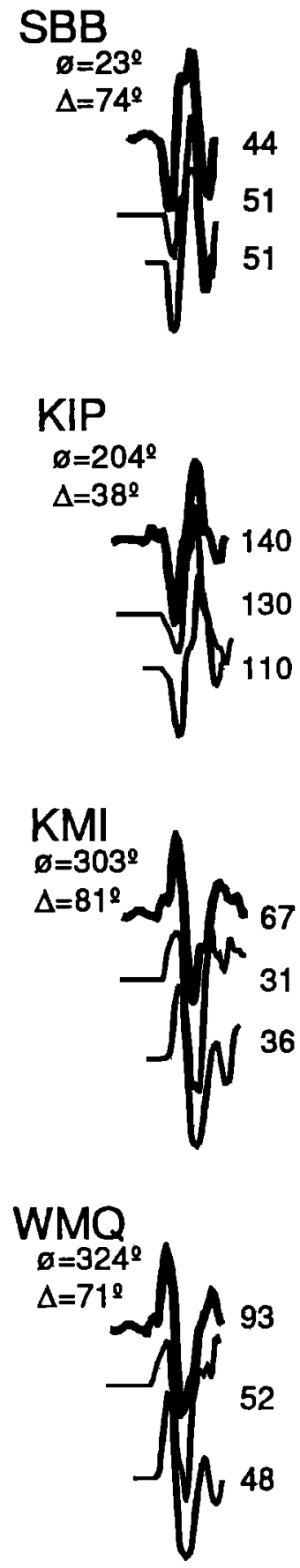
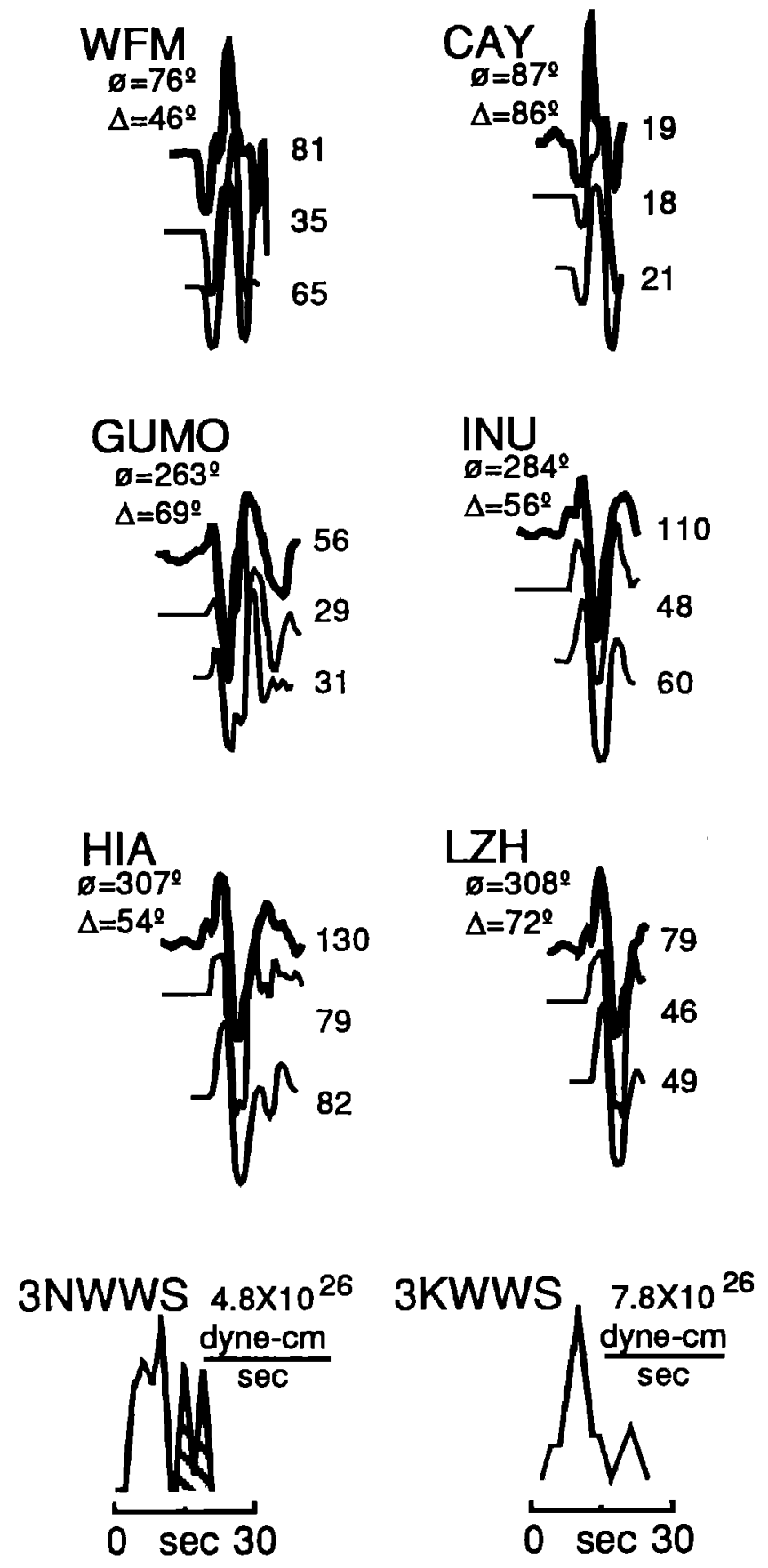

Fig. C4. Observed (heavy lines) and synthetic WWS $P$ wave seismograms for model $3 N W W S$ and model 3KWWS. The unhatched regions represent the percentage of moment contributed by 3NWWS.1 and hatched regions by 3NWWS.2. Symbols are explained in Figure C2.

best fit focal mechanisms are stable and well determined (Figure C7). The correlation functions are again elongated along strike but form an isolated peak near $10 \mathrm{~km}$ west of the epicenter. The focal mechanisms are nearly identical during the first $15 \mathrm{~s}$ of the event. However, even though this appears to be a simple event, a single focal mechanism still cannot explain the data.

In model $3 \mathrm{KWWS}$, the focal mechanisms are allowed to vary in time for five iterations. Figures C4 and C5 show the data and synthetics for this model. The overall match 


\section{March 1988 SH waves}
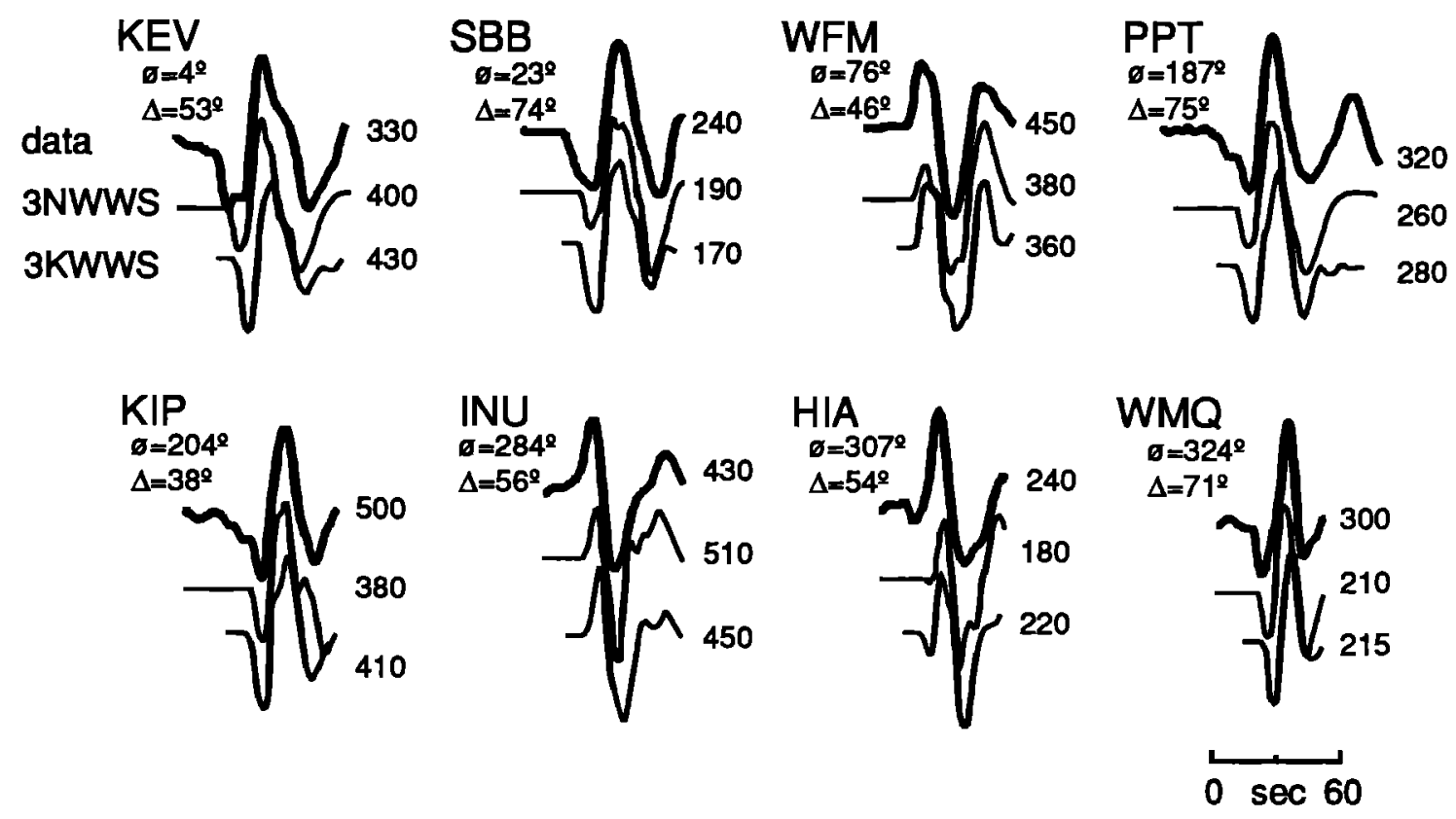

Fig. C5. Observed (heavy lines) and synthetic WWS $S H$ wave seismograms for model 3 NWWS and model 3KWWS. Symbols are explained in Figure C2.

06 March 1988

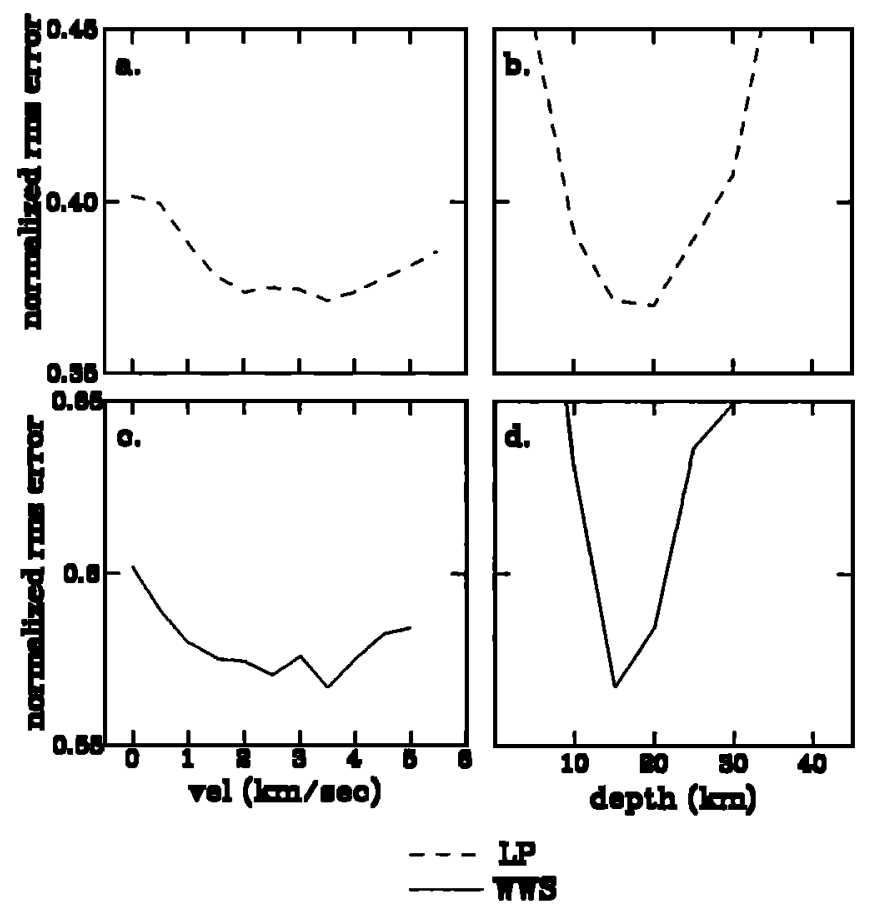

Fig. C6. Data misfits for method N. Plotted are the normalized rms errors versus: (a) velocity for a fixed centroid depth of $15 \mathrm{~km},(b)$ centroid depth for a fixed velocity of $3.5 \mathrm{~km} / \mathrm{s}$ for the LP data, (c) velocity for a fixed centroid depth of $15 \mathrm{~km}$, and $(d)$ centroid depth for a fixed velocity of $3.5 \mathrm{~km} / \mathrm{s}$ for the WWS data.

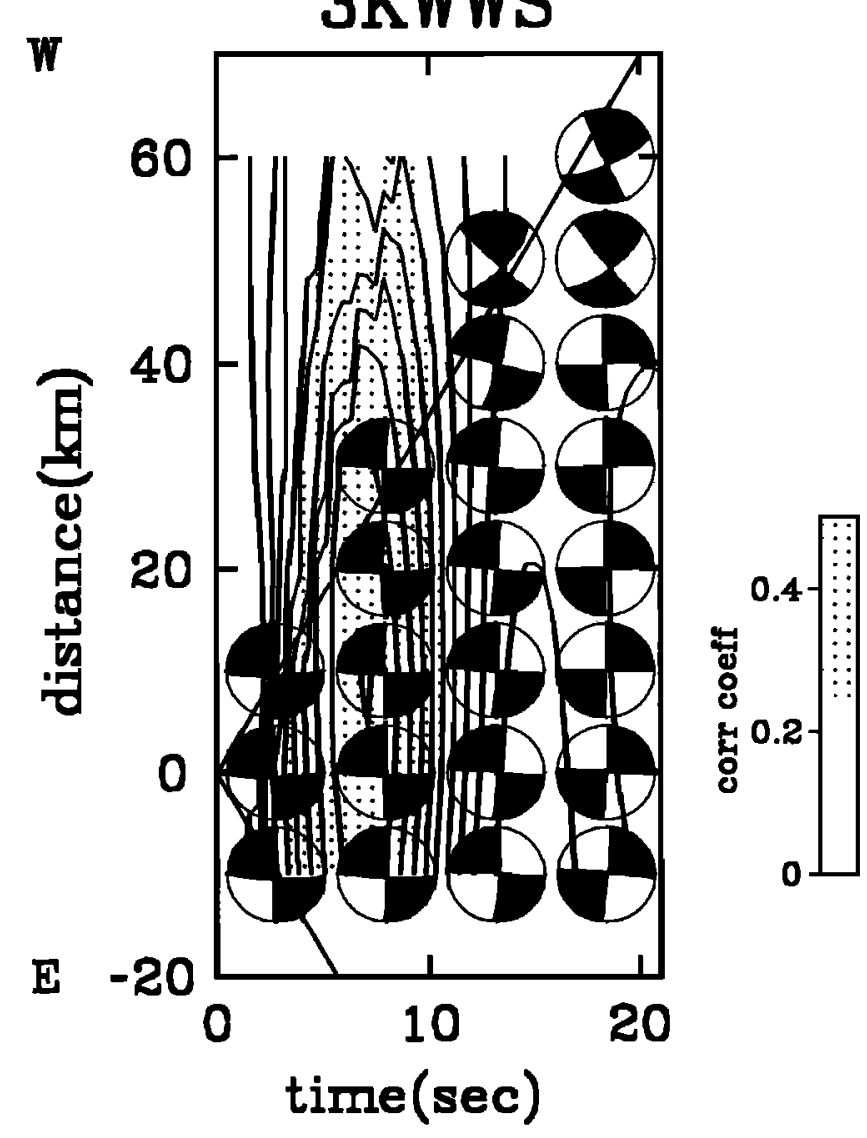

Fig. C7. 3KWWS. Layout is described in Figure A7. 
TABLE C1. March 6, 1988, Summary of Source Parameters for Event 3

\begin{tabular}{|c|c|c|c|c|c|c|c|c|c|c|}
\hline Model & $\begin{array}{c}\text { Strike, } \\
\text { deg }\end{array}$ & $\begin{array}{l}\text { Dip, } \\
\text { deg }\end{array}$ & $\begin{array}{c}\text { Rake, } \\
\text { deg }\end{array}$ & $\begin{array}{c}\text { Depth, } \\
\text { km }\end{array}$ & $\begin{array}{c}\text { Delay, } \\
\mathbf{s}\end{array}$ & $\begin{array}{c}\text { Velocity, } \\
\mathbf{k m} / \mathbf{s}\end{array}$ & $\begin{array}{c}\text { Distance, } \\
\mathbf{k m}\end{array}$ & $\begin{array}{c}\text { Azimuth, } \\
\text { deg }\end{array}$ & $\begin{array}{r}\text { Mom } \\
\text { dyn cm }\end{array}$ & $10^{27}$ \\
\hline$\overline{\text { 3NLP.1 }}$ & 181 & 62 & 186 & 15 & & $\overline{3.5}$ & & 268 & 3.2 & \\
\hline 3NLP.2 & 184 & 80 & 170 & 15 & 13 & & & & 1.7 & (4.9) \\
\hline 3NWWS.1 & 179 & 79 & 187 & 15 & & 3.5 & & 268 & 2.9 & \\
\hline $3 N W W S .2$ & 189 & 97 & 176 & 15 & 13 & & & & 1.5 & (4.4) \\
\hline \multirow[t]{6}{*}{ 3KLP } & 182 & 74 & 180 & 20 & & $3.5^{\#}$ & & & 3.9 & \\
\hline & 183 & 82 & 183 & 20 & 8 & & 20 & 180 & 2.5 & \\
\hline & 163 & 58 & 191 & 10 & 2 & & 10 & 180 & 0.8 & \\
\hline & 192 & 78 & 179 & 30 & 16 & & 10 & 180 & 0.6 & \\
\hline & 170 & 77 & 174 & 20 & 2 & & 0 & 180 & 0.5 & \\
\hline & 330 & 76 & 1 & 20 & 11 & & 40 & 0 & 0.5 & (4.9) \\
\hline \multirow[t]{6}{*}{ 3KWWS } & 176 & 81 & 189 & 10 & & $3.5^{\#}$ & & & 4.3 & \\
\hline & 180 & 87 & 185 & 10 & 6.8 & & 10 & 268 & 2.0 & \\
\hline & 182 & 83 & 186 & 30 & 8.0 & & 10 & 88 & 1.1 & \\
\hline & 171 & 74 & 197 & 10 & 2.8 & & 10 & 268 & 0.7 & \\
\hline & 178 & 89 & 179 & 10 & 10.8 & & 20 & 268 & 0.8 & \\
\hline & 164 & 43 & -91 & 50 & 17.6 & & 10 & 268 & 1.0 & $(5.6)$ \\
\hline
\end{tabular}

See text and Table A1.

"Fixed.

\# Maximum rupture velocity.

to the waveforms is good, but the amplitudes are underpredicted. For this model, most of the moment release lies within a depth of 10 to $20 \mathrm{~km}$ and within a distance of $20 \mathrm{~km}$ from the epicenter. The focal mechanisms for the different subevents in the first $10 \mathrm{~s}$ are consistently leftlateral strike-slip on the east-west trending plane with the focal parameters varying up to $10^{\circ}$. The best double-couple sum has a scalar moment of $4.3 \times 10^{27}$ dyn $\mathrm{cm}$ with a large nondouble-couple component of $21 \%$. A complete description of all subevents is given in Table C1.

The last iteration in the solution introduces the large nondouble couple component. It improves the errors by $7 \%$ from the previous step and noticeably improves the waveforms. This subevent occurs late at $18 \mathrm{~s}$ and has a normal mechanism that is not well resolved. Without it, the best scalar moment remains almost the same, $4.4 \times 10^{27} \mathrm{dyn} \mathrm{cm}$, but now has a very small nondouble couple component, $<1 \%$.

Acknowledgements. We thank J. Lahr and C. Stephens for sharing their first motion data and aftershock relocations with us. Many thanks to Jeanne Sauber as well as several anonymous reviewers for their time and diligence in catching many of the egregious prethesis and postthesis errors and their suggestions which tremendously improved the presentation of this paper. This work was supported by an NSF Graduate Fellowship and the U.S. Geological Survey under contract 14-08-0001G1170. This is contribution 5031 of the Division of Geological and Planetary Sciences, California Institute of Technology.

\section{REFERENCES}

Anderson, H. J., and J. Zhang, Long-period seismic radiation from the May 23, 1989, Macquarie Ridge earthquake: Evidence for coseismic slip in the mantle?, J. Geophys. Res., $96,19,853-19,863,1991$.

Atwater, T., and J. Severinghaus, Tectonic maps of the northeast Pacific, in The Geology of North America, vol. N, The Eastern Pacific Ocean and Hawaii, edited by E. L. Winterer, D. M. Hussong, and R. W. Decker, Pp. 15-20, Geological Society of America, Boulder, Colo., 1989.

Braunmiller, J., and J. Nábłlek, Rupture process of the Macquarie Ridge earthquake of May 23, 1989, Geophys. Res. Lett., 17, 1017-1020, 1990.

Bruns, T. R., P. R. Carlson, A. J. Stevenson, M. A. Fisher, H. F. Ryan, and D. M. Mann, GLORIA images for the Gulf of Alaska and British Columbia: Subduction zones, transforms, and channels (abstract), Eos Trans. AGU, 70, $1338,1989$.

Buland, R., and J. Taggart, A mantle wave magnitude for the St. Elias, Alaska, earthquake of 28 February 1979, Bull. Seismol. Soc. Am., 71, 1143-1159, 1981.

Butler, R., G. S. Stewart, and H. Kanamori, The July 27, 1976 Tangshan, China earthquake-A complex sequence of intraplate events, Bull. Seismol. Soc. Am., 69, 207-220, 1979.

DeMets, C., R. G. Gordon, D. F. Argus, and S. Stein, Current plate motions, Geophys. J. Int., 101, 425-478, 1990.

Deschamps, A., P. Bernard, M. Bezzeghoud, T. Monfret, and B. Romanowicz, The Alaskan earthquakes of November 17 and 30, 1987: Very long period and broad band analysis of quasi-real time teletransmitted Geoscope data (abstract), Eos Trans. AGU, 69, 400, 1988.

Dietz, L. D., and W. L. Ellsworth, The October 17, 1989 Loma Prieta, California earthquake and its aftershocks: Geometry of the sequence from high-resolution locations, Geophys. Res. Lett., 17, 1417-1420, 1990.

Doser, D. I., and H. Kanamori, Depth of seismicity in the Imperial Valley region 1977-1983 and its relationship to heat flow, crustal structure, and the October 15, 1979, earthquake, J. Geophys. Res., 91, 675-688, 1986.

Dziewonski, A. M., and G. Zwart, The Macquarie Ridge earthquake of 23 May 1989 (abstract), Eos Trans. AGU, 70, 1196, 1990.

Dziewonski, A. M., G. Ekstrom, J. H. Woodhouse, and G. Zwart, Centroid-moment tensor solutions for October-December 1987, Phys. Earth Planet. Inter., 54, 10-21, 1989 a.

Dziewonski, A. M., G. Ekstrom, J. H. Woodhouse, and G. Zwart, Centroid-moment tensor solutions for January-March 1988, Phys. Earth Planet. Inter., 54, 22-32, 19896.

Dziewonski, A. M., G. Ekstrom, J. H. Woodhouse, and G. Zwart, Centroid-moment tensor solutions for January-March 1989, Phys. Earth Planet. Inter., 60, 243-253, 1990.

Eaton, J. P., M. E. O'Neill, and J. N. Murdock, Aftershocks of the 1966 Parkfield-Cholame, California, earthquake: A detailed study, Bull. Seismol. Soc. Am., 60, 1151-1197, 1970.

Ekström, G., and B. Romanowicz, The 23 May 1989 Macquarie Ridge earthquake: A very broad band analysis, Geophys. Res. Lett., 17, 993-996, 1990.

Engeln, J. F., D. A. Wiens, and S. Stein, Mechanisms and depths of Atlantic transform earthquakes, J. Geophys. Res., 91, $548-577,1986$.

Espinosa, A. F., R. Husid, and A. Quesada, Intensity distribution and source parameters from field observations: The Guatemalan earthquake of February 4, 1976, A preliminary report, U.S. Geol. Surv. Prof. Pap., 1002, 52-66, 1976. 
Furumoto, M., and I. Nakanishi, Source times and scaling relations of large earthquakes, J. Geophys. Res., 88, 2191$2198,1983$.

Given, D. D., Master event relocations of the North Palm Springs earthquake sequence of July 1986 (abstract), Eos Trans. $A G U, 67,1089,1986$.

Goetze, C., and B. Evans, Stress and temperature in the bending lithosphere as constrained by experimental rock mechanics, Geophys. J. R. Astron. Soc., 59, 463-478, 1979.

Hartzell, S. H., and T. H. Heaton, Rupture history of the 1984 Morgan Hill, California, earthquake from the inversion of strong motion records, Bull. Seismol. Soc. Am., 76, 649 $674,1986$.

Hwang, L. J., Teleseismically determined source parameters of several large collision zone earthquakes, $\mathrm{Ph} . \mathrm{D}$. dissertation, 190 pp., Calif. Inst. of Technol., Pasadena, 1991.

Hwang, L. J., H. Magistrale, and H. Kanamori, Teleseismic source parameters and rupture characteristics of the 24 November 1987, Superstition Hills earthquake, Bull. Seismol. Soc. Am., 80, 43-56, 1990.

Johnson, C. E., and D. M. Hadley, Tectonic implications of the Brawley earthquake swarm, Imperial Valley, California, January 1975, Bull. Seismol. Soc. Am., 66, 1131-1144, 1976.

Johnson, C. E., and L. K. Hutton, Aftershocks and preearthquake seismicity, in The Imperial Valley, California, Earthquake of October 15, 1979, U.S. Geol. Surv. Prof. Pap., 1254, 59-76, 1982.

Jones, L. M., L. K. Hutton, D. D. Given, and C. R. Allen, The North Palm Springs, California earthquake sequence of July 1986, Bull. Seismol. Soc. Am., 76, 1830-1837, 1986.

Kanamori, $H$., The energy release in great earthquakes, $J$. Geophys. Res., 82, 2981-2987, 1977.

Kanamori, H., and D. L. Anderson, Theoretical basis of some empirical relations in seismology, Bull. Seismol. Soc. Am., $65,1073-1095,1975$.

Kanamori, H., and K. Satake, Broadband study of the 1989 Loma Prieta earthquake, Geophys. Res. Lett., 17, 11791182,1990

Kanamori, H., and G. S. Stewart, Seismological aspects of the Guatemala earthquake of February 4, 1976, J. Geophys. Res., 83, 3427-3434, 1978.

Kedar, S. and T. Tanimoto, Moment of the Macquarie Island earthquake from free oscillation data (abstract), Eos Trans. $A G U, 71,558,1990$.

Kikuchi, M., and H. Kanamori, Inversion of complex body waves, Bull. Seismol. Soc. Am., 72, 491-506, 1982.

Kikuchi, M., and H. Kanamori, Inversion of complex body waves - III, Bull. Seismol. Soc. Am., 81, 2335-2350, 1991.

Knopoff, L., Energy release in earthquakes, Geophys. J. R. Astron. Soc., 1, 44-52, 1958.

Lahr, J. C., and G. Plafker, Holocene Pacific-North American plate interaction in southern Alaska: Implications for the Yakataga seismic gap, Geology, 8, 483-486, 1980.

Lahr, J. C., R. A. Page, C. D. Stephens, and D. H. Christensen, Unusual earthquakes in the Gulf of Alaska and fragmentation of the Pacific plate, Geophys. Res. Lett., 15, 14831486, 1988.

Langston, C. A., The effect of planar dipping structure on source and receiver responses for constant ray parameter, Bull. Seismol. Soc. Am., 67, 1029-1050, 1977.

Leeds, A. K., E. G. Kausel, and L. Knopoff, Variations of upper mantle structure under the Pacific Ocean, Science, 186, 141-143, 1974.

Lindh, A., and D. M. Boore, The relation of the Parkfield foreshocks to the initiation and extent of rupture, Earthquake Notes, 45, 54, 1974.

Magsitrale, H., L. Jones, and H. Kanamori, The Superstition Hills, California, earthquakes of 24 November, 1987, Bull. Seismol. Soc. Am., 79, 239-251, 1989.

McCann, W. R., O. J. Perez, and L. R. Sykes, Yakataga Gap, Alaska: Seismic history and earthquake potential, Science, 207, 1309-1314, 1980.

Minster, J. B., and T. H. Jordan, Present-day plate motions, J. Geophys. Res., 83, 5331-5354, 1978.

Nábł̌lek, J., Determination of earthquake source parameters from inversion of body waves, Ph.D. dissertation, Mass. Inst. of Technol., Cambridge, 1984.
Nábělek, J., Geometry and mechanism of faulting of the 1980 El Asnam, Algeria, earthquake from inversion of teleseismic body waves and comparison with field observations, $J$. Geophys. Res., 90, 12,713-12,728, 1985.

Parsons, B., and J. G. Sclater, An analysis of the variation of ocean floor bathymetry and heat flow with age, J. Geophys. Res., 82, 803-827, 1977.

Perez, O. J., and K. H. Jacob, Tectonic model and seismic potential of the eastern Gulf of Alaska and Yakataga seismic gap, J. Geophys. Res., 85, 7132-7150, 1980.

Plafker, G., Tectonics of the March 27, 1964 Alaska earthquake, U.S. Geol. Surv. Prof. Pap., 543-I, 1969.

Plakker, G., Tectonic aspects of the Guatemala earthquake of 4 February 1976, Science, 193, 1201-1208, 1976.

Plafker, G., T. Hudson, T. Bruns, and M. Rubin, Late Quaternary offsets along the Fairweather fault and crustal plate interactions in southern Alaska, Can. J. Earth Sci., 15, 805-816, 1978.

Satake, K., and H. Kanamori, Fault parameters and tsunami excitation of the May 23, 1989, Macquarie ridge earthquake, Geophys. Res. Lett., 17, 997-1000, 1990.

Schwartz, S. Y., J. W. Dewey, and T. Lay, Influence of fault plane heterogeneity on the seismic behavior in the Southern Kurile Islands Arc, J. Geophys. Res., 94, 5637-5649, 1989.

Sykes, L. R., Aftershock zones of great earthquakes, seismicity gaps, and earthquake prediction for Alaska and the Aleutians, J. Geophys. Res., 76, 8021-8041, 1971.

Sykes, L. R., Intraplate seismicity, reactivation of preexisting zones of weakness, alkaline magmatism and other tectonism postdating continental fragmentation, Rev. Geophys., 16, $621-668,1978$.

Sykes, L. R., J. B. Kisslinger, L. House, J. N. Davies, and K. H. Jacob, Rupture zones and repeat times of great earthquakes along the Alaska-Aleutian arc, 1784-1980, in Earthquake Prediction, An International Review, Maurice Ewing Ser., vol. 4, edited by D. W. Simpson and P. B. Richards, pp. 73-80, AGU, Washington, D.C., 1981.

Tichelaar, B. W. and L. J. Ruff, Rupture process and stress-drop of the great 1989 Macquarie Ridge earthquake, Geophys. Res. Lett., 17, 1001-1004, 1990.

Tocher, D., The Alaska earthquake of July 10, 1958: Movement on the Fairweather fault and field investigation of southern epicentral region, Bull. Seismol. Soc. Am., 50, 267-292, 1960.

von Huene, R., G. G. Shor, Jr., and J. Wageman, Continental margins of the eastern Gulf of Alaska and boundaries of tectonic plates, AAPG Mem., 29, 272-290, 1979.

Wald, D. J., D. V. Helmberger, and S. H. Hartzell, Rupture process of the 1987 Superstition Hills earthquake from the inversion of strong motion data, Bull. Seismol. Soc. Am., $80,1079-1098,1990$.

Watts, A. B., J. H. Bodine, and M. S. Steckler, Observations of flexure and the state of stress in the oceanic lithosphere, $J$. Geophys. Res., 85, 6369-6376, 1980.

Wiens, D. A., and S. Stein, Age dependence of oceanic intraplate seismicity and implications for lithospheric evolution, $J$. Geophys. Res., 88, 6455-6468, 1983.

Wiens, D. A., and S. Stein, Intraplate seismicity and stresses in young oceanic lithosphere, J. Geophys. Res., 89, 11,442$11,464,1984$.

Wilson, D. S., A kinematic model for the Gorda Deformation Zone as a diffuse southern boundary of the Juan de Fuca plate, J. Geophys. Res., 91, 10,259-10,269, 1986.

Young, C. J., T. Lay, and C. S. Lynnes, Rupture of the 4 February 1976 Guaternalan earthquake, Bull. Seismol. Soc. Am., $79,670-689,1989$.

Zhang, J., and H. Kanamori, Source finiteness of large earthquakes measured from long-period Rayleigh waves, Phys. Earth Planet. Inter., 52, 56-84, 1988.

L. J. Hwang, U.S. Geological Survey, 525 S. Wilson, Pasadena, CA 91106.

H. Kanamori, Division of Geological and Planetary Sciences, California Institute of Technology, Pasadena, CA 91125.

(Received June 7, 1991;

revised July 20, 1992;

accepted July 23, 1992.) 